\title{
Phenological sensitivity to climate across taxa and trophic levels
}

Stephen J. Thackeray ${ }^{1}$, Peter A. Henrys ${ }^{1}$, Deborah Hemming ${ }^{2}$, James R. Bell ${ }^{3}$, Marc S. Botham ${ }^{4}$, Sarah Burthe ${ }^{5}$, Pierre Helaouet $^{6}$, David G. Johns ${ }^{6}$, Ian D. Jones ${ }^{1}$, David I. Leech ${ }^{7}$, Eleanor B. Mackay ${ }^{1}$, Dario Massimino ${ }^{7}$, Sian Atkinson ${ }^{8}$, Philip J. Bacon ${ }^{9}$, Tom M. Brereton ${ }^{10}$, Laurence Carvalho ${ }^{5}$, Tim H. Clutton-Brock ${ }^{11}$, Callan Duck ${ }^{12}$, Martin Edwards ${ }^{6}$, J. Malcolm Elliott ${ }^{13}$, Stephen J. G. Hall ${ }^{14}$, Richard Harrington ${ }^{3}$, James W. Pearce-Higgins ${ }^{7}$, Toke T. Høye ${ }^{15}$, Loeske E. B. Kruuk ${ }^{16,17}$, Josephine M. Pemberton ${ }^{16}$, Tim H. Sparks ${ }^{18,19}$, Paul M. Thompson ${ }^{20}$, Ian White ${ }^{21}$, Ian J. Winfield ${ }^{1}$ \& Sarah Wanless ${ }^{5}$

\begin{abstract}
Differences in phenological responses to climate change among species can desynchronise ecological interactions and thereby threaten ecosystem function. To assess these threats, we must quantify the relative impact of climate change on species at different trophic levels. Here, we apply a Climate Sensitivity Profile approach to 10,003 terrestrial and aquatic phenological data sets, spatially matched to temperature and precipitation data, to quantify variation in climate sensitivity. The direction, magnitude and timing of climate sensitivity varied markedly among organisms within taxonomic and trophic groups. Despite this variability, we detected systematic variation in the direction and magnitude of phenological climate sensitivity. Secondary consumers showed consistently lower climate sensitivity than other groups. We used mid-century climate change projections to estimate that the timing of phenological events could change more for primary consumers than for species in other trophic levels (6.2 versus 2.5-2.9 days earlier on average), with substantial taxonomic variation (1.1-14.8 days earlier on average).
\end{abstract}

Numerous long-term ecological changes have been attributed to climate change ${ }^{1}$. Shifts in the seasonal timing of recurring biological events such as reproduction and migration (that is, phenological changes) have been especially well documented ${ }^{2,3}$. Long-term ecosystem studies $^{4-7}$ and global meta-analyses ${ }^{2,3,8}$ have demonstrated that many spring and summer phenological events now occur earlier in the year than they did previously. Substantial among-species variation in responses has fuelled concerns that key seasonal interactions among species may desynchronize over time, with potentially severe consequences for wild populations and, hence, for ecosystem functioning 9 .

Identifying systematic taxonomic and trait-based differences in phenological climate sensitivity (that is, change in seasonal timing per unit change in climatic conditions) would have substantial socio-ecological implications. Such knowledge would afford some predictability to future ecological outcomes and would identify species that represent effective sentinels of climate impact, facilitating the development of indicators and estimates of vulnerability for conservation and national adaptation programmes ${ }^{10-12}$. Unfortunately, such generalizations are currently elusive.

\section{Analytical approach and data sets}

Among-species differences in phenological change may arise from two aspects of climate sensitivity. First, variation may reflect differences in physiological and behavioural responses, microclimate use, and the importance of non-climate-related cues, such as photoperiod ${ }^{13}$ or resource availability ${ }^{14}$. Thus, even if species are most sensitive to climate change during the same seasonal period (window), they show different phenological responses to a given climatic change. Second, co-occurring species may vary in their seasonal periods of climate sensitivity, each being typified by different levels of directional climate change ${ }^{15-17}$. We conceptualize these two aspects of phenological responses as species-specific (or population-specific) climate sensitivity profiles (CSPs; Fig. 1). The CSP approach differs fundamentally from attempts to identify single 'critical' seasonal periods within which climatic change most strongly affects seasonal events ${ }^{17}$, by quantifying the full range of phenological responses to seasonal climatic change. We ask, "How sensitive are phenological events to temperature and precipitation change at different times of year?". By applying this approach to a large, taxonomically diverse, national-scale data set, we discern coherent patterns within a multitude of idiosyncratic biological climate responses. We assess whether systematic differences in climate sensitivity underpin differences in phenological change among taxonomic and trophic groups in the $\mathrm{UK}^{8}$.

We elected against using published climate responses that may be biased in favour of species showing an effect. Instead, we analysed 10,003 long-term ( $\geq 20$-year) phenological time series for 812 marine, freshwater and terrestrial taxa over the period 1960-2012. Our data set aggregates many of the UK's foremost long-term biological monitoring schemes (Supplementary Table 1), including phenological information on amphibians (spawning), birds (egg laying, migration), planktonic

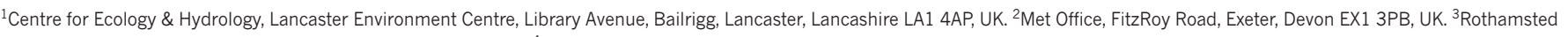
Research, West Common, Harpenden, Hertfordshire AL5 2JQ, UK. ${ }^{4}$ Centre for Ecology \& Hydrology, Maclean Building, Benson Lane, Crowmarsh Gifford, Wallingford, Oxfordshire OX10 8BB, UK. ${ }^{5}$ Centre for Ecology \& Hydrology, Bush Estate, Penicuik, Midlothian EH26 OQB, UK. ${ }^{6}$ The Sir Alister Hardy Foundation for Ocean Science, The Laboratory, Citadel Hill, Plymouth, Devon PL1 2PB, UK. ${ }^{7}$ British Trust for Ornithology, The Nunnery, Thetford, Norfolk IP24 2PU, UK. ${ }^{8}$ The Woodland Trust, Kempton Way, Grantham, Lincolnshire NG31 6LL, UK. ${ }^{9}$ Futtie Park, Banchory, Aberdeen

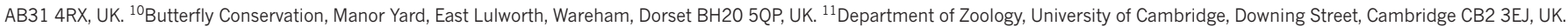
${ }^{12}$ Sea Mammal Research Unit, Scottish Oceans Institute, East Sands, University of St Andrews, St Andrews, Fife KY16 8LB, UK. ${ }^{13}$ The Freshwater Biological Association, The Ferry Landing,

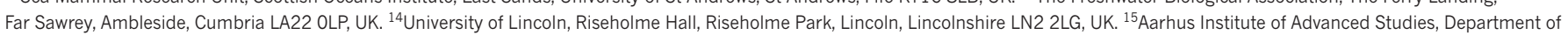
Bioscience and Arctic Research Centre, Aarhus University, Høegh-Guldbergs Gade 6B, DK-8000 Aarhus C, Denmark. ${ }^{16}$ Institute of Evolutionary Biology, School of Biological Sciences, University of Edinburgh, Edinburgh EH9 3FL, UK. ${ }^{17}$ Research School of Biology, The Australian National University, ACT 2612 Australia. ${ }^{18}$ Faculty of Engineering and Computing, Coventry University,

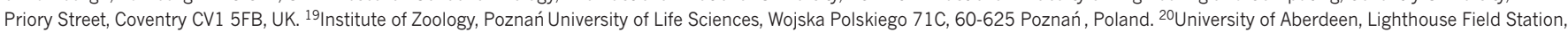
George Street, Cromarty, Ross-shire IV11 8YJ, UK. ${ }^{21}$ People's Trust for Endangered Species, 15 Cloisters House, 8 Battersea Park Road, London SW8 4BG, UK.
} 

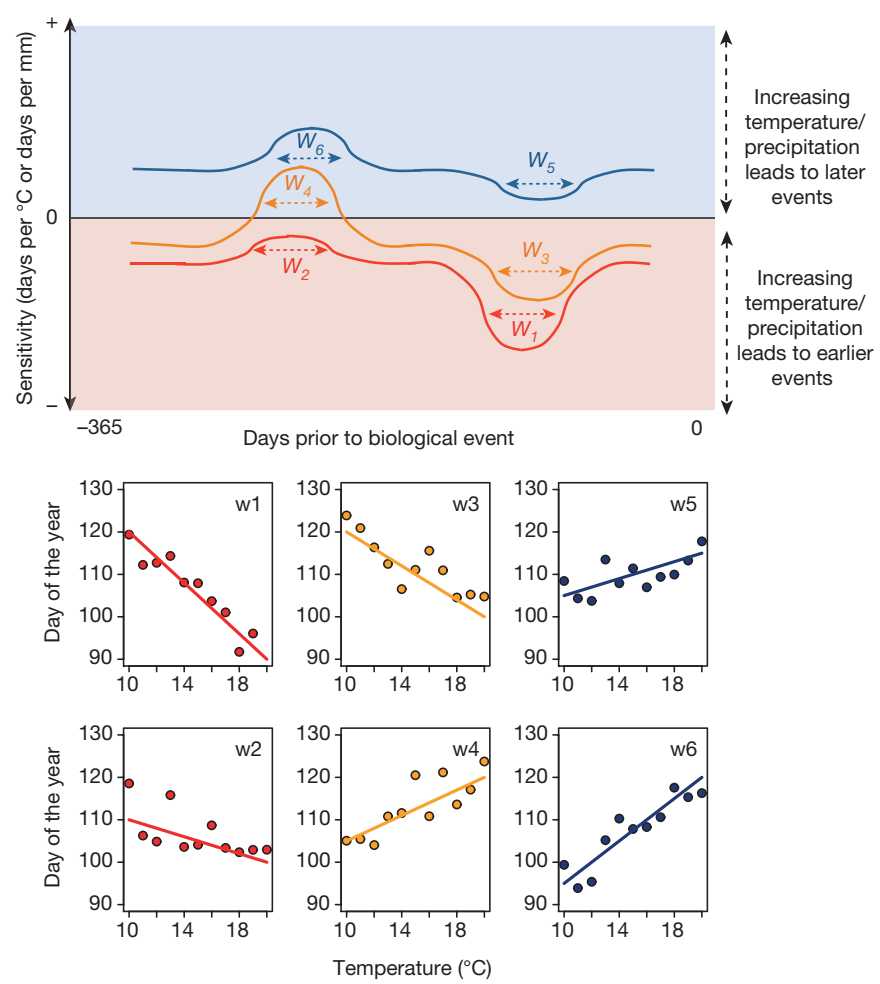

Figure 1 | Climate sensitivity profiles. Climate sensitivity is the change in seasonal timing per unit change in temperature (days per ${ }^{\circ} \mathrm{C}$ ) or precipitation (days per $\mathrm{mm}$ ). Irrespective of the date, increasing temperature or precipitation might always correlate with earlier (red curve; CSP type I) or later (blue curve; CSP type III) biological events, but the sensitivity to climate variation (correlation magnitude) can differ (compare w1 and w2, w5 and w6). By contrast, opposing climatephenology correlations can occur, depending on the date at which the climate changes (orange curve, w3 and w4; CSP type II). Panels show hypothetical relationships for seasonal windows w1-w6.

crustaceans (population peaks), fish (spawning, migration), insects (flight periods), mammals (birth dates), phytoplankton (population peaks) and plants (flowering, fruiting, leafing). These taxa represent three broad trophic levels: primary producers (phytoplankton and plants), primary consumers (granivorous birds, herbivorous insects, mammals and planktonic crustaceans) and secondary consumers (predatory amphibians, birds, fish, insects, mammals and planktonic crustaceans). We spatially matched all 10,003 phenological time series with local temperature and precipitation data from a $5 \times 5-\mathrm{km}$ resolution gridded data set, before statistically modelling the relationship between seasonal timing and climatic variables. Between 1960 and 2012, mean UK air temperature increased in all months, and mean precipitation increased in most months (Fig. 2a).

Spatial variability in climatic change (Fig. 2b, c) necessitates local matching of phenological and climatic data sets rather than the use of regionally averaged climate data (for example, Central England Temperatures) or large-scale climatic indicators (for example, North Atlantic Oscillation). We did not make the restrictive assumption that biological events would be related to annual mean climatic conditions, or to conditions within periods based upon calendar months. Our CSP approach identified seasonal periods within which climatic change had the most positive and negative correlations with phenology (hereafter referred to as upper and lower limits of climate sensitivity, respectively). We could identify, for each phenological series, up to two seasonal periods within which climatic variation had a marked correlation with seasonal timing. The method was flexible enough to allow situations in which climatic variation within only a single period had a marked correlation with seasonal timing, and to identify seasonal windows ranging from a few days to a whole year in length. Our analysis captured the idiosyncrasies of phenological responses, allowed us to categorize them into generic types of climate response, and is consistent with current biological understanding of climate-phenology relationships ${ }^{15,16}$.

\section{Climate response types in the UK}

CSPs fall into three categories. The qualitative type of climatephenology correlation (positive or negative) may remain consistent, irrespective of when in the year climatic change occurs. In this case only the magnitude of the phenological response differs with the time of year at which climatic variables change. The climate-phenology correlation may be consistently negative (CSP type I; Fig. 1, red curve) or positive (CSP type III; Fig. 1, blue curve). Alternatively, opposing correlations between seasonal climatic change and the timing of biological events may exist; that is, the direction and magnitude of the phenological response may vary (CSP type II; Fig. 1, orange curve). We determined CSPs for responses to temperature $\left(\mathrm{CSP}_{\text {temp }}\right)$ and precipitation ( $\left.\mathrm{CSP}_{\text {precip }}\right)$.

Among responses to temperature changes, CSP type II was most common (Extended Data Table 1; 69.7\% of phenological series). Seasonal events were advanced by (that is, negatively correlated with) warming during one period of the year, and delayed by (that is, positively correlated with) warming in another period. After multiple testing correction, $44.8 \%$ of the observed phenological advances (but only $1.0 \%$ of delays) with warming were statistically significant $(P<0.05)$. CSP type I was the next most common response type: warming in different seasonal windows was consistently correlated with earlier seasonal events (that is, negative correlations; $24.7 \%$ of series). In this case the lower and upper limits of CSPs represent the 'strongest' and 'weakest' phenological advances with warming, respectively, and $58.1 \%$ of the 'strongest' responses were statistically significant $(P<0.05$, correcting for multiple testing).

Phenological events most commonly demonstrated opposing (Fig. 1; CSP type II, 53.0\% of series) or consistently positive (Fig. 1; CSP type III, $28.0 \%$ of phenological series) correlations with increasing seasonal precipitation. Although delayed phenological events may commonly be associated with higher precipitation ( $81.0 \%$ of events show this type of response), few of these associations were statistically significant (Extended Data Table 1).

\section{Climate sensitivity at the UK-wide scale}

We matched each phenological series with four climate variables: mean temperature during the seasonal windows at the upper and lower limits of $\mathrm{CSP}_{\text {temp }}$, and similarly averaged precipitation data for the seasonal

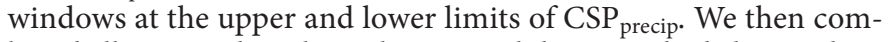
bined all 10,003 phenological series and their matched climate data, and modelled the relationships between seasonal timing and climate variables using linear mixed effects (LME) models. Initially we fitted a 'global' model to quantify the upper and lower limits of temperature and precipitation sensitivity, averaged across all phenological events. Marine plankton data were excluded at this stage, owing to a lack of precipitation data.

Most phenological events occurred earlier with seasonal warming (average rate -2.6 days per ${ }^{\circ} \mathrm{C}$; Fig. $3 \mathrm{a}$ and Extended Data Table 2). Variation in the strength of this correlation was similar among sites and species (random-effects variances in site and species level seasonal timing-temperature slopes were 2.1 and 1.9, respectively). Some phenological events occurred later with seasonal warming (Fig. 3a) although, in other cases, the upper limit of CSP temp was in fact a 'weak' advance with warming. The upper limit of temperature sensitivity was more variable among species than among sites (random effects variances in species and site level seasonal timing-temperature slopes were 2.3 and 0.4, respectively). Averaged across species and populations, temperature responses were most consistent with CSP type II.

Most phenological events showed opposing responses to increasing seasonal precipitation (Fig. 1; CSP type II). The tendency for 


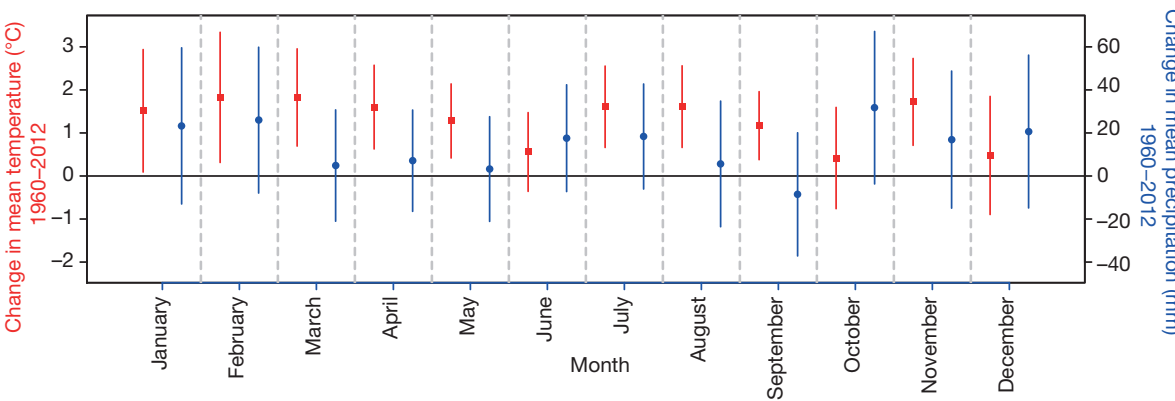

b
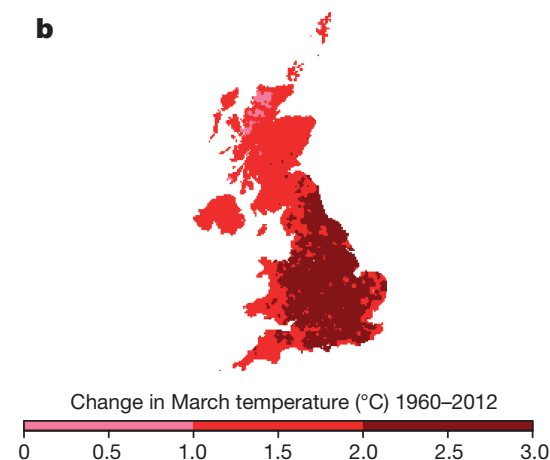

c

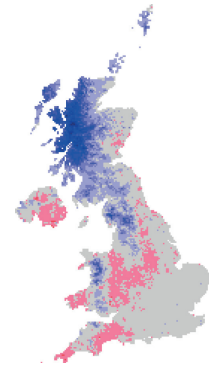

Change in February precipitation (mm) 1960-2012
Figure 2 | Climatic change in the UK, 1960-2012. a, Long-term changes in air temperature and precipitation are the differences between the 1960 and 2012 monthly means of these variables, derived from a regression fitted through each monthly time series. Error bars indicate the standard deviation of linearly detrended climatological data, as an indication of inter-annual variation around each trend. b, c, Examples of spatial variation in the extent of long-term climatic changes are shown for March air temperatures (b) and February precipitation (c). delays with rising precipitation was greatest: the average upper limit of $\mathrm{CSP}_{\text {precip }}$ exceeded the lower limit ( 1.4 days per $\mathrm{mm}$ and -0.4 days per mm, respectively; Fig. $3 \mathrm{~b}$ and Extended Data Table 2). The upper limit of $\mathrm{CSP}_{\text {precip }}$ was more variable among species than among sites (species and site level random-effects variances in the seasonal timingprecipitation slopes were 1.9 and 1.2, respectively). The fitted climatephenology model was better supported by the data than a year-only model with the same random effects structure ( $\triangle \mathrm{AIC}$ (Akaike's information criterion) 293,516). This indicates the presence of real associations between climate and seasonality, rather than purely spurious correlations resulting from shared temporal trends. Average sensitivity to temperature was very similar in the model that included marine plankton data, but excluded precipitation effects (see Supplementary Discussion and Extended Data Fig. 1).

\section{Taxonomic and trophic group sensitivity}

We tested the hypothesis that the limits of seasonal climate sensitivity differ coherently among taxonomic groups by including a fixedeffect interaction between taxonomic group and each climatic variable (Fig. 4 and Extended Data Table 2). The lower limit of CSP temp was negative for all groups ('earliness' with warming), the strongest responses being found for plants, freshwater phytoplankton, insects and amphibians (4.3, 4.1, 3.7 and 3.4 days earlier per ${ }^{\circ} \mathrm{C}$, respectively). The upper limits of $\mathrm{CSP}_{\text {temp }}$ indicated that freshwater phytoplankton and mammals experienced the greatest phenological delays with seasonal warming (2.9 and 2.0 days later per ${ }^{\circ} \mathrm{C}$, respectively) but that plants showed little evidence of such delays. The strongest phenological delays with rising seasonal precipitation were found for freshwater phytoplankton and insects ( 2.5 and 2.2 days later per $\mathrm{mm}$, respectively), while freshwater phytoplankton also exhibited the strongest phenological advances with rising precipitation during other seasonal windows (1.1 days earlier per $\mathrm{mm}$ ). Average temperature and precipitation responses were consistent with CSP type II in most cases. There was considerable within-group variability in sensitivity.

We examined trophic-level differences in climate sensitivity by including trophic level in interaction with each climate variable in the global model. The lower limit of $\mathrm{CSP}_{\text {temp }}$ showed greater systematic variation than the upper limit among trophic levels (Fig. 3c, e). The tendency towards 'earliness' with seasonal warming was strongest at lower trophic levels $\left(-4.1,-3.7\right.$ and -1.9 days per ${ }^{\circ} \mathrm{C}$ for primary producers, primary consumers and secondary consumers, respectively; Extended Data Table 2), consistent with observations of more rapid phenological changes at lower trophic levels, in the $\mathrm{UK}^{8}$. Conversely, the lower limit of $\mathrm{CSP}_{\text {precip }}$ varied less than the upper limit among trophic levels (Fig. 3d, f). The tendency for seasonal events to be later with higher seasonal precipitation was greater for primary producers and primary consumers (1.8 and 2.2 days per mm on average, respectively) than for secondary consumers (1.0 days per $\mathrm{mm}$ ). Variations in climate
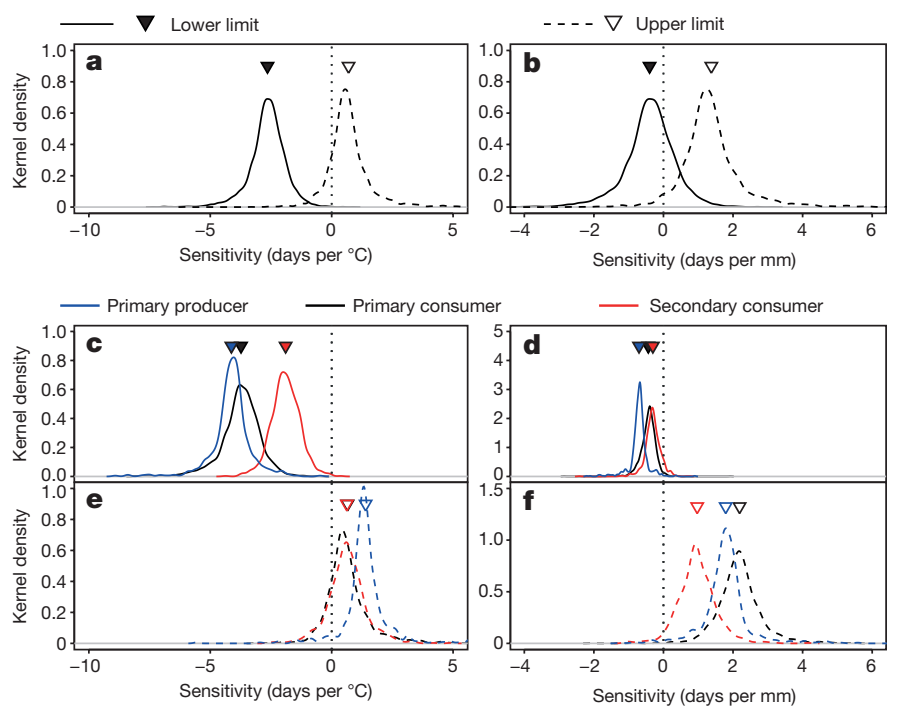

Figure 3 | Upper and lower limits of phenological climate sensitivity. Sensitivity is the slope of the relationship between seasonal timing (day of year) and climatic variables. a, b, All-taxa upper and lower limits in sensitivity to temperature $\left({ }^{\circ} \mathrm{C}\right.$; $\left.\mathbf{a}\right)$ and precipitation $(\mathrm{mm}$ per day; $\mathbf{b})$ are summarized. $\mathbf{c}-\mathbf{f}$, Lower $(\mathbf{c}, \mathbf{d})$ and upper $(\mathbf{e}, \mathbf{f})$ limits of sensitivity to temperature $(\mathbf{c}, \mathbf{e})$ and precipitation $(\mathbf{d}, \mathbf{f})$ are shown by trophic level. Inverted triangles indicate average sensitivity. Curves are kernel density plots: estimates of the probability density distribution of species-level climate sensitivity (that is, the relative likelihood of different levels of climate sensitivity within each species group) $(n=370,725)$. 


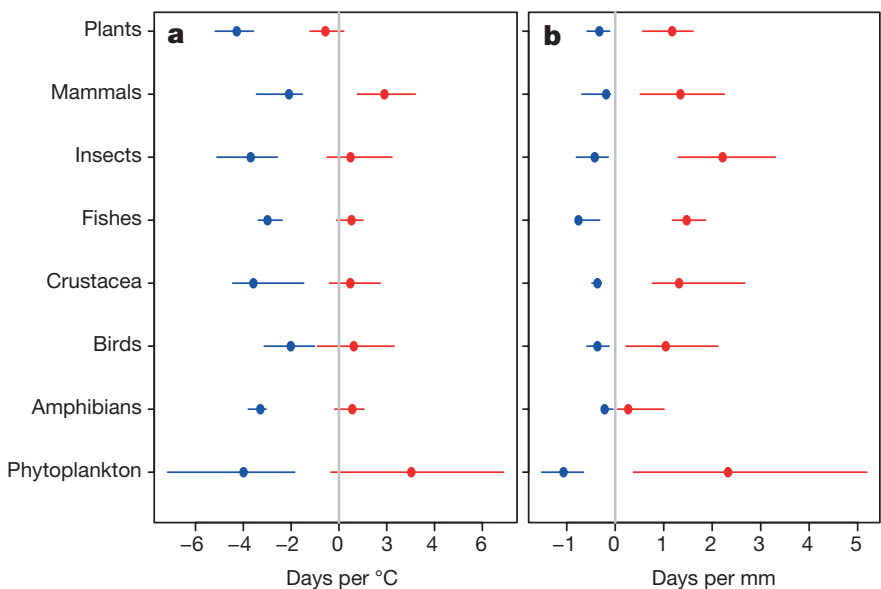

Figure 4 | Upper and lower limits of phenological climate sensitivity for broad taxonomic groups. a, b, Lower (blue) and upper (red) limits of the sensitivity of phenological events to seasonal temperature (a) and precipitation (b) change are shown. Coloured circles indicate the median response, and bars show the 5th-95th percentile responses for each group. Sensitivity is quantified by summarizing the species-level (random effects) responses from a mixed effects model including data for all taxa, and with taxonomic group as a fixed effect $(n=370,725)$.

sensitivity were described more parsimoniously by taxonomic groups than by trophic levels (AICs of taxonomic and trophic-level models $3,237,611$ and 3,238,061, respectively).

The results were affected little when we analysed only pre- and post1980 data, to minimize among-group variation in time series length, and after Monte Carlo re-sampling to assess the potential effects of taxonomic bias (see Supplementary Discussion and Extended Data Figs 2-4). The same qualitative trophic-level differences in climate sensitivity were apparent when we included marine plankton data in a temperature-only LME model (see Supplementary Discussion and Extended Data Fig. 1). In contrast to trophic-level differences in the magnitude of sensitivity, there was little evidence of similar variation in the seasonal timing of climate sensitivity (see Supplementary Discussion and Extended Data Figs 5-7).

\section{Estimating future change}

Overall, net phenological responses to climatic change combine potentially opposing responses to conditions in different seasonal periods. We estimated net responses by the 2050s by applying our fitted models to UKCP09 probabilistic projections (bias-corrected relative to a 1961-1990 baseline) of temperature and precipitation change under low-, medium- and high-emissions scenarios. Rather than predicting the absolute timing of future phenological events, we contrasted possible changes in seasonal timing among organism groups based upon established climate scenarios and contemporary patterns of climate sensitivity. Estimated average phenological changes were less for primary producers and secondary consumers than for primary consumers (Fig. 5a). This occurred because, averaged across species, the opposing climate responses of primary producers and secondary consumers are more similar in magnitude than are those of primary consumers (Fig. 3), effectively cancelling each other out. Our models suggest greater average advances for crustacea, fish and insects than for other groups, such as freshwater phytoplankton, birds and mammals (Fig. 5b). However, response variation is high for crustacea (Fig. 5b).

\section{Discussion}

In the UK, phenological climate sensitivity varies greatly, suggesting that it is influenced by locally varying, non-climatic drivers such as population structure ${ }^{18}$, resource availability ${ }^{19}$ and adaptation ${ }^{20}$. This is relevant to the use of phenological change as a tangible climate change
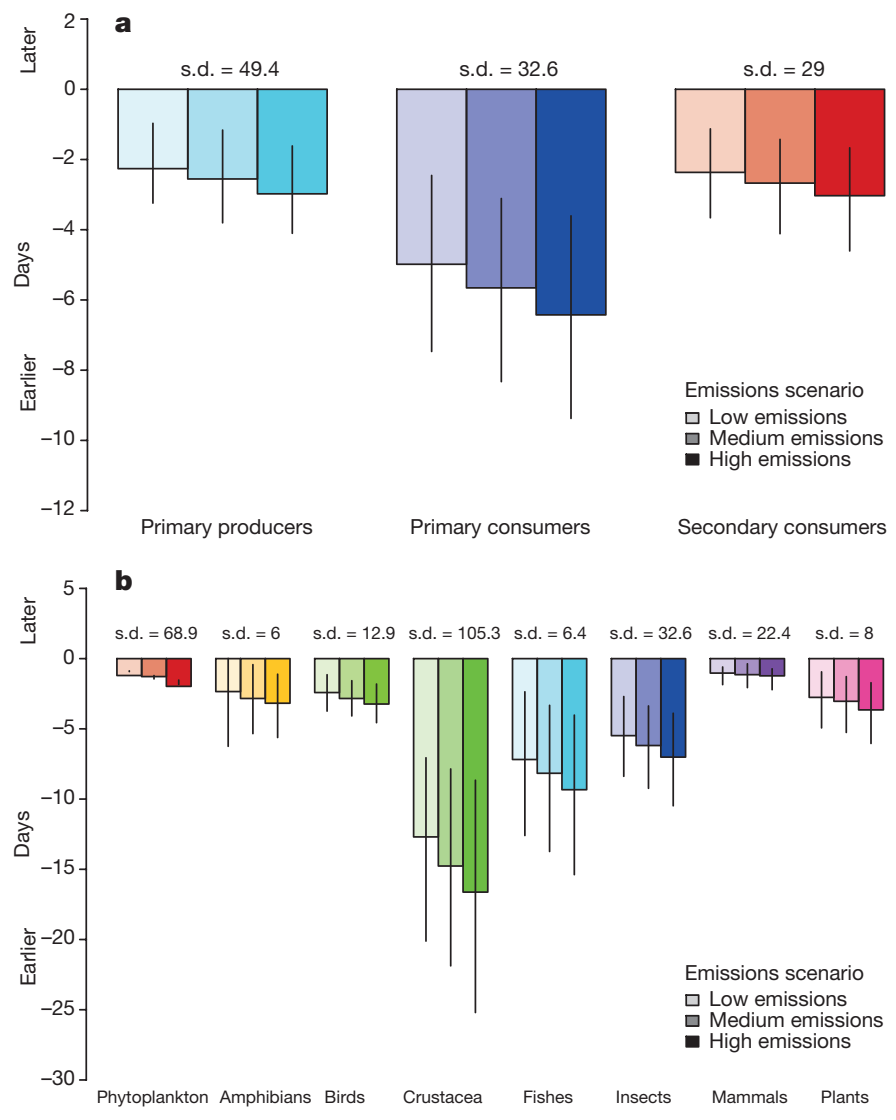

Figure 5 | Estimated phenological shifts by the 2050s. a, b, Modelled responses to projected temperature and precipitation change, assuming contemporary climate sensitivity, for trophic levels (a) and taxonomic groups (b). Projected median shifts in seasonal timing are shown. Change estimates are based on low-, medium- and high-emissions climate scenarios. Bars represent median responses to 50th percentile climate change projections under each scenario; extremes of whiskers represent median responses to the 10th and 90th percentile projected climatic changes under each scenario. Standard deviations indicate variation in projected responses for each group under the 50th percentile of the medium-emissions scenario.

indicator ${ }^{1,21}$. Mediators of phenological climate sensitivity are known only locally for some of the groups in our data set (for example, nutrient availability for freshwater phytoplankton $)^{22}$. However, for others, the climate sensitivity of different biological traits is known to be mediated by alternative drivers ${ }^{23,24}$. High climate response variability necessitates wide site and species coverage in long-term monitoring schemes designed to develop robust aggregate indicators of change ${ }^{21}$. As climatic conditions are more spatially variable across broader geographic domains, site-level replication of phenological monitoring is particularly important when interpreting phenology at continental-to-global scales. In the UK, average responses for fish and insects appear to be sensitive indicators of climate effects. These groups show consistently strong phenological advances with seasonal warming, and only weak opposing responses, resulting in relatively large (net) changes in seasonal timing. Interpretation of phenological changes for other groups is more complex. For example, freshwater phytoplankton show strong evidence of opposing phenological responses to climatic variation at different times of year and these responses are near-equivalent in magnitude, such that estimated net changes are negligible. This finding emphasizes that long-term observations represent the net effect of potentially opposing biological responses ${ }^{25}$. To fully capitalize on the indicator potential of phenological change, we must advance our mechanistic understanding of responses to potentially opposing climatic and non-climatic drivers. 
Despite this variability, we identified coherent patterns in climate sensitivity among the idiosyncratic responses of many wild plant and animal populations. We have shown that, on average, species in different trophic levels differ in the magnitude of seasonal climate sensitivity, but not in the time of year within which climatic change has its most pronounced effects. This may be a key mechanism underpinning observations of trophic level differences in phenological change in the $\mathrm{UK}^{8}$. Lower trophic levels demonstrated more pronounced variation in their sensitivity to changing temperature and precipitation at different times of year, and stronger phenological responses to climatic change during defined (taxon- and population-specific) seasonal periods.

In response to climatic changes projected for the 2050s, relative changes in seasonal timing are likely to be greatest for primary consumers, particularly in the terrestrial environment. The difference in magnitude between opposing climate responses is greatest for primary consumers, resulting in greater net change. Our approach makes the simplifying assumption that climatic change has an overriding influence upon seasonality. Nevertheless, our results suggest that systematic differences in climate sensitivity could result in widespread phenological desynchronization. However, factors that shape phenological climate responses introduce uncertainty into projections of future phenological change. These results should catalyse research to improve predictive capacity in the face of multiple environmental and demographic drivers that not only mediate rates of change, but might also confer resilience to desynchronization (for example, population density dependence ${ }^{26}$, compensatory range shifts ${ }^{27}$, and the formation of novel inter-specific interactions ${ }^{28,29}$ ). These findings also underscore the importance of developing our capacity to manage ecosystems within a 'safe operating space' with respect to the likely impacts of projected climate change ${ }^{30}$.

Online Content Methods, along with any additional Extended Data display items and Source Data, are available in the online version of the paper; references unique to these sections appear only in the online paper.

Received 12 June 2015; accepted 26 May 2016.

Published online 29 June 2016.

1. IPCC. Climate Change 2014: Impacts, Adaptation, and Vulnerability. Part A: Global and Sectoral Aspects. Contribution of Working Group II to the Fifth Assessment Report of the Intergovernmental Panel on Climate Change 1132 (Cambridge Univ. Press, 2014).

2. Parmesan, C. \& Yohe, G. A globally coherent fingerprint of climate change impacts across natural systems. Nature 421, 37-42 (2003).

3. Root, T. L. et al. Fingerprints of global warming on wild animals and plants. Nature 421, 57-60 (2003).

4. Both, C., van Asch, M., Bijlsma, R. G., van den Burg, A. B. \& Visser, M. E. Climate change and unequal phenological changes across four trophic levels: constraints or adaptations? J. Anim. Ecol. 78, 73-83 (2009).

5. Visser, M. E., Holleman, L. J. M. \& Gienapp, P. Shifts in caterpillar biomass phenology due to climate change and its impact on the breeding biology of an insectivorous bird. Oecologia 147, 164-172 (2006).

6. Burthe, S. et al. Phenological trends and trophic mismatch across multiple levels of a North Sea pelagic food web. Mar. Ecol. Prog. Ser. 454, 119-133 (2012).

7. Jonsson, T. \& Setzer, M. A freshwater predator hit twice by the effects of warming across trophic levels. Nat. Commun. 6, 5992 (2015).

8. Thackeray, S. J. et al. Trophic level asynchrony in rates of phenological change for marine, freshwater and terrestrial environments. Glob. Change Biol. 16, 3304-3313 (2010)

9. Visser, M. E. \& Both, C. Shifts in phenology due to global climate change: the need for a yardstick. Proc. R. Soc. Lond. B 272, 2561-2569 (2005).

10. Walpole, M. et al. Ecology. Tracking progress toward the 2010 biodiversity target and beyond. Science 325, 1503-1504 (2009).

11. Butchart, S. H. M. et al. Global biodiversity: indicators of recent declines. Science 328, 1164-1168 (2010).

12. Williams, S. E., Shoo, L. P., Isaac, J. L., Hoffmann, A. A. \& Langham, G. Towards an integrated framework for assessing the vulnerability of species to climate change. PLoS Biol. 6, e325 (2008).

13. Post, E. \& Forchhammer, M. C. Climate change reduces reproductive success of an Arctic herbivore through trophic mismatch. Philos. Trans. R. Soc. B Biol. Sci. 363, 2367-2373 (2008).
14. Thackeray, S. J., Jones, I. D. \& Maberly, S. C. Long-term change in the phenology of spring phytoplankton: species-specific responses to nutrient enrichment and climatic change. J. Ecol. 96, 523-535 (2008).

15. Doi, H., Gordo, O. \& Katano, I. Heterogeneous intra-annual climatic changes drive different phenological responses at two trophic levels. Clim. Res. 36, 181-190 (2008)

16. Visser, M. E., van Noordwijk, A. J., Tinbergen, J. M. \& Lessells, C. M. Warmer springs lead to mistimed reproduction in great tits (Parus major). Proc. R. Soc Lond. B 265, 1867-1870 (1998).

17. van de Pol, M. \& Cockburn, A. Identifying the critical climatic time window that affects trait expression. Am. Nat. 177, 698-707 (2011).

18. Ohlberger, J., Thackeray, S., Winfield, I., Maberly, S. \& Vøllestad, L. When phenology matters: age-size truncation alters population response to trophic mismatch. Proc. R. Soc. Lond. B 281, 20140938 (2014).

19. Thackeray, S. J., Henrys, P. A., Jones, I. D. \& Feuchtmayr, H. Eight decades of phenological change for a freshwater cladoceran: what are the consequences of our definition of seasonal timing? Freshw. Biol. 57, 345-359 (2012).

20. Phillimore, A. B., Hadfield, J. D., Jones, O. R. \& Smithers, R. J. Differences in spawning date between populations of common frog reveal local adaptation. Proc. Natl Acad. Sci. USA 107, 8292-8297 (2010); correction 109, 5134 (2012).

21. Amano, T., Smithers, R. J., Sparks, T. H. \& Sutherland, W. J. A 250-year index of first flowering dates and its response to temperature changes. Proc. R. Soc. Lond. B 277, 2451-2457 (2010).

22. Feuchtmayr, H. et al. Spring phytoplankton phenology - are patterns and drivers of change consistent among lakes in the same climatological region? Freshw. Biol. 57, 331-344 (2012).

23. Nussey, D. H., Clutton-Brock, T. H., Albon, S. D., Pemberton, J. \& Kruuk, L. E. B. Constraints on plastic responses to climate variation in red deer. Biol. Lett. 1, 457-460 (2005)

24. Van Emden, H. F. \& Harrington, R. Aphids as Crop Pests. 717 (CABI, 2007).

25. Cook, B. I., Wolkovich, E. M. \& Parmesan, C. Divergent responses to spring and winter warming drive community level flowering trends. Proc. Natl Acad. Sci. USA 109, 9000-9005 (2012).

26. Reed, T. E., Grøtan, V., Jenouvrier, S., Sæther, B.-E. \& Visser, M. E. Population growth in a wild bird is buffered against phenological mismatch. Science 340, 488-491 (2013).

27. Amano, T. et al. Links between plant species' spatial and temporal responses to a warming climate. Proc. R. Soc. Lond. B 281, 20133017 (2014).

28. Miller-Rushing, A. J., Hoye, T. T., Inouye, D. W. \& Post, E. The effects of phenological mismatches on demography. Philos. Trans. R. Soc. B 365, 3177-3186 (2010)

29. Nakazawa, T. \& Doi, H. A perspective on match/mismatch of phenology in community contexts. Oikos $\mathbf{1 2 1}$, 489-495 (2012).

30. Scheffer, M. et al. Creating a safe operating space for iconic ecosystems. Science 347, 1317-1319 (2015).

Supplementary Information is available in the online version of the paper.

Acknowledgements This work was funded by Natural Environment Research Council (NERC) grant NE/J02080X/1. We thank O. Mountford for assigning species traits for plants. H. Feuchtmayr for extracting plankton data for analysis and N. Dodd for air and water temperature data from the Tarland Burn. We also thank P. Verrier, the staff and many volunteers and contributors, including Science and Advice for Scottish Agriculture, to the Rothamsted Insect Survey (RIS) over the last half century. The RIS is a National Capability strategically funded by BBSRC. The consortium represented by the authorship list hold long-term data that represent a considerable investment in scientific endeavour. Whilst we are committed to sharing these data for scientific research, users are requested to collaborate before publication of these data to ensure accurate biological interpretation.

Author Contributions S.J.T. and S.W. conceived and coordinated the study and led writing of the manuscript. P.A.H. developed the analysis routine and wrote statistical code to be applied to all data sets. D.H. extracted all climatic and sea surface temperature data. I.D.J. and E.B.M. calculated water temperatures for lakes and streams, respectively. S.J.T., J.R.B., M.S.B., S.B., P.H., T.T.H., D.G.J., D.I.L., E.B.M. and D.M. led analysis of specific data sets using code from P.A.H. S.A., P.J.B., T.M.B., L.C., T.H.C.-B., C.D., M.E., J.M.E., S.J.G.H., R.H., J.W.P.-H., L.E.B.K., J.M.P., T.H.S., P.M.T., I.W. and I.J.W. derived phenological data for analysis, advised on interpretation, and assisted in assigning species traits. All co-authors commented on the manuscript.

Author Information Reprints and permissions information is available at www.nature.com/reprints. The authors declare no competing financial interests. Readers are welcome to comment on the online version of the paper. Correspondence and requests for materials should be addressed to S.J.T. (sjtr@ceh.ac.uk).

Reviewer Information Nature thanks D. Inouye, M. Visser and the other anonymous reviewer(s) for their contribution to the peer review of this work. 


\section{METHODS}

Data sets. We integrated data from many major UK biological monitoring schemes (Supplementary Table 1), resulting in 10,003 long-term (at least 20 years between 1960 and 2012) phenological series for 812 marine, freshwater and terrestrial taxa. The amassed data sets included records for plants, phytoplankton, zooplankton, insects, amphibians, fish, mammals and birds $(379,081$ individual phenological observations). For each study we used a single population-level phenological measure per year (Supplementary Table 1). Because the sampling resolution for the marine plankton data was monthly, before analysis we re-scaled these data into units of days. Trophic level, taxonomic class and environmental affinity were assigned to each taxon, to permit analyses of correlations between these attributes and climate sensitivity.

Daily air temperature and precipitation data were extracted from the Met Office National Climate Information Centre (NCIC) 5-km-resolution gridded data set ${ }^{31}$ for the spatial locations of all biological monitoring sites across the UK land surface. If available, recorded water temperatures from the same sites were used in place of air temperatures for phenological time series representing obligate aquatic taxa (freshwater plankton and fish). Water temperatures were interpolated onto a daily time-step before analysis ${ }^{32}$. If these data were not available, daily water temperature data were estimated from air temperatures using a fitted empirical site-specific relationship between air and water temperature. For the sea trout (Salmo trutta) data, an existing linear relationship ${ }^{33}$ was used, while for the Atlantic salmon (Salmo salar) data, a nonlinear relationship ${ }^{34}$ was calculated for a nearby river, the Tarland Burn, and applied to air temperatures from the sampling site. For the marine plankton, mean monthly sea surface temperatures were extracted from the Met Office Hadley Centre Sea Ice and Sea Surface Temperature (HadISST) data set $^{35}$ for each of the Standard Areas ${ }^{36}$ in which phenological data were available. Precipitation data were not available for marine Standard Areas.

Statistics. Our analysis was conducted in two distinct phases (see Supplementary Notes). First, the CSP for each phenological series was estimated using generalized linear models to quantify associations between the timing of seasonal events and mean temperature and precipitation (within defined seasonal time windows) at the same location. Second, the phenological time series were aggregated and a single LME model was run, capturing upper and lower limits of climate sensitivity across many species. CSPs for precipitation were not estimated for marine plankton data (see above), so the second-phase LME models were run twice: once to examine correlations with temperature and precipitation for all but the marine plankton phenological series ( 9,800 series), and once to examine only correlations with temperature for the whole data set (10,003 series).

Phase 1: Estimating CSPs for each time series. We used consistent methods to 'screen' all phenological events with respect to their climate sensitivity, finding periods of the year in which temperature and precipitation had the most positive and negative correlations with seasonal timing (the upper and lower limits of climate sensitivity). This approach was flexible enough to detect when these limits represented opposing correlations between temperature or precipitation and seasonality, depending upon the seasonal timing of climatic change; for example, spring warming may advance budburst, but winter warming may delay it ${ }^{37}$ (Fig. 1 CSP type II). This approach could also detect when the direction of the correlation between climatic variables and seasonal timing was consistent irrespective of the seasonal timing of climatic change, with only the magnitude of the correlation varying between the limits of the CSP (Fig. 1; CSP types I and III).

For each phenological time series, we calculated the day of the year by which $95 \%$ of the recorded seasonal events had occurred (doy95). Inter-annual variations in seasonal timing were statistically modelled as a function of daily mean temperatures on doy $_{95}$ each year. Then, a series of 365 statistical models was run that instead used daily mean temperatures on doy $_{95}-1$ to doy ${ }_{95}-365$ as predictors. Slope coefficients and $R^{2}$ values for the temperature terms in these models were collated, capturing seasonal variations in the sign and magnitude of the phenology-temperature relationship (that is, the CSP; Fig. 1). Generalized linear models (GLMs) were used.

For two data sets (BTO Nest Record Scheme and PTES National Dormouse Monitoring Scheme; Supplementary Table 1) we modified the above analytical framework. In both of these schemes, the precise location of the biological observations changed among years (compared with other schemes in which monitoring sites were static over time). We extracted matching climatic data for each specific location in each year, as for all other schemes, but then grouped the phenological and climatic data at county level (mean area $3,440 \mathrm{~km}^{2}$ ). Then, for each taxon in each county we used the fixed-effect slope parameters and $R^{2}$ values from a series of LME models, instead of GLMs, as a basis for estimating CSPs. In these models, we included fixed effects of temperature on doy $_{95}$ to doy d5 $^{-365}$ as before, and included a year random effect to account for replicate phenological records for each taxon in each county in each year. For the SAHFOS marine plankton data set, we modified our iterative approach to analyse seasonal timing-temperature relationships at monthly, instead of daily, time steps (the temporal resolution of the sea surface temperature data).

As a final step in estimating the CSP for each series, temporal variation in the sign and magnitude of the seasonal timing-temperature correlation was itself modelled (Extended Data Fig. 8). This was done by fitting generalized additive models (GAMs, gamma error distribution) to the time series of slope coefficients and $R^{2}$ values from the models described above. By smoothing these time series, the GAMs identified periods of the year in which slope coefficients were consistently negative (that is, warming advanced seasonal timing), or consistently positive (that is, warming delayed seasonal timing), and during which the climate-phenology models generating the slope estimates had a their highest goodness-of-fit.

Seasonal windows in which the upper and lower limits of temperature sensitivity occurred were identified as periods during which: 1 ) the $95 \%$ confidence interval for the GAM fitted to the slope coefficients surpassed the limits of the 2.5th and 97.5th percentiles of the original slope coefficients; and 2) the $95 \%$ confidence interval for the GAM fitted to the $R^{2}$ values surpassed the 97.5th percentile of the original $R^{2}$ values. This ensured that seasonal windows were defined by periods combining the greatest climate effect size and relatively strong predictive power (determined by $R^{2}$ ). Using this framework, we identified the lower limit of CSP temp: the period of the year in which an advancing effect of increasing temperature upon seasonal timing was most likely. This was estimated by determining when the $95 \%$ confidence interval of the GAM intersected the lower percentile of the seasonal timing-temperature slope coefficients, by tracking the most negative coefficients (Extended Data Fig. 8). In addition, we identified the upper limit of CSP temp by determining when the $95 \%$ confidence interval of the GAM intersected the upper percentile of the seasonal timing-temperature slope coefficients, by tracking the most positive (or least negative) coefficients. Excluding the marine plankton data, the whole modelling process was repeated with precipitation as a predictor instead of air temperature, culminating in the estimation of seasonal periods capturing the limits of phenological responses to changing precipitation.

After this process, temperature and precipitation were each averaged within the two seasonal windows in which the limits of phenological sensitivity occurred. With the exception of the marine plankton data, the final seasonal timing-climate model for each series was then fitted using a GLM with gamma error distribution including four predictors: inter-annual variations in 1) mean temperature during the period at the lower limit of $\mathrm{CSP}_{\text {temp, }}$ 2) mean temperature during the period at the upper limit of $\left.\mathrm{CSP}_{\text {temp }}, 3\right)$ mean precipitation during the period at the lower limit of $\mathrm{CSP}_{\text {precip, }}$ 4) mean precipitation during the period at the upper limit of $\mathrm{CSP}_{\text {precip. }}$. For the marine plankton data, only the first two terms were fitted. For the BTO Nest Record and PTES National Dormouse Monitoring Scheme data sets we implemented these final models in a mixed effects framework with a random effect of year, as before. Therefore, although we modelled changes in statistical parameters (which are not estimated without error) to identify seasonal periods, this step was used only to find the original climatic data to be used in subsequent modelling. Inferences were not, therefore, directly based upon statistical modelling of uncertain parameter estimates. We categorized the results of all 10,003 CSPs according to three broad response types (CSP types I-III; Fig. 1), and retained $P$ values for each fitted model term to infer which of the modelled climatic effects were statistically significant. We examined the evidence for trophic-level differences in the mean seasonal timing of climate sensitivity by modelling the relationship between the start date, end date and duration of the seasonal windows capturing the upper and lower limits of phenological sensitivity to temperature and rainfall as a function of trophic level (fixed effect), with random effects of phenological metric, within species, within site. Analyses were conducted using the base, $m g c v$ and lmes packages in R (refs 38-40).

Phase 2: Global models of phenological climate sensitivity. We estimated the upper and lower limits of phenological climate sensitivity at a multi-species scale by matching each phenological series with data on mean temperature and precipitation, during the seasonal windows characterizing the CSP for that series (Phase 1, above). We aggregated all 10,003 of these matched phenology-climate data sets. To quantify the average, multi-species, upper and lower limits of climate sensitivity we constructed an LME model in which phenology (day of year) was modelled as a function of mean temperature and precipitation within the seasonal windows of the amassed CSPs (fixed effects) with random effects of phenological metric, within species, within site. These random effects were necessary because our data could not be considered independent. The timings of events are more likely to be similar for the same species than for different species; the same is true for different sites and the phenological metric-types used to describe the events (for example, first flight time or seasonal peak abundance). Random slopes and intercepts were allowed to ensure that each phenological event, for a species at a site, was allowed a different rate of climate response. 
For some species, more than one phenological event was recorded in the same year, at the same site. For example, butterflies may have more than one flight period in the same year, and plankton populations may be characterized by more than one seasonal abundance peak. As climate responses are unlikely to be the same for the first event of the year and subsequent events, we introduced a voltinism factor in the analysis. This allowed us to distinguish between data representing the first or only events of each year (for example, a spring plankton bloom or butterfly generation) and second events in each year (for example, the subsequent summer plankton bloom or butterfly generation). This distinction captured all possibilities within our data set.

For site $i$, species $j$, voltmetric $k$ (where voltmetric is a unique combination of voltinism class and the metric-type used to identify the event), the corresponding day of year (DOY) of a particular seasonal event is modelled as:

$$
\mathrm{DOY}_{i j k}=\alpha_{0}+\beta_{1} \mathrm{TL}_{i j k}+\beta_{2} \mathrm{TU}_{i j k}+\beta_{3} \mathrm{PL}_{i j k}+\beta_{4} \mathrm{PU}_{i j k}+\varepsilon_{i j k}
$$

where $\varepsilon_{i j k} \sim N\left(0, \sigma^{2}\right)$ and the model includes temperature at the upper limit of each CSP (TU), temperature at the lower limit of each CSP (TL), precipitation at the upper limit of each CSP (PU) and precipitation at the lower limit of each CSP (PL). Owing to the non-independence within the data, we allow the intercepts and coefficients corresponding to all four covariates to vary by site, species and voltmetric. Preserving the natural nesting of a metric for a species at a particular site, this gives:

$$
\begin{aligned}
& \alpha_{0}=\gamma_{0}+\mu_{0 ; i j k}+\mu_{0 ; i j, k}+\mu_{0 ; i, j k} \\
& \beta_{1}=\gamma_{1}+\mu_{1 ; i j k}+\mu_{1 ; i j, k}+\mu_{1 ; i, j k} \\
& \beta_{2}=\gamma_{2}+\mu_{2 ; i j k}+\mu_{2 ; i j, k}+\mu_{2 ; i, j k} \\
& \beta_{3}=\gamma_{3}+\mu_{3 ; i j k}+\mu_{3 ; i j, k}+\mu_{3 ; i, j k} \\
& \beta_{4}=\gamma_{4}+\mu_{4 ; i j k}+\mu_{4 ; i j, k}+\mu_{4 ; i, j k}
\end{aligned}
$$

where each of the $\mu$ terms is a normally distributed random effect.

This nesting of random effects is most conservative in terms of inference at the global level and is as flexible as possible, allowing each time series to have its own set of model parameters. This permits a high degree of biological realism because each distinct phenological event, for a given species, at a given site, is permitted to have a different slope for the effects of temperature and precipitation (that is, a different climate sensitivity).

In this model framework we are specifically testing the null hypotheses that each of the climate variables shows no relation to the seasonal timing of biologica events. Because of this, and the fact that each parameter is estimated directly, without distributional form assumed a priori or as the target distribution, we follow a frequentist approach to analysis. However, because the exact degrees of freedom cannot be evaluated when using restricted maximum likelihood, and hence no exact $P$ values can be obtained, we present full summaries of all the parameters estimated at species level (as given by $\gamma+\mu_{i j k}+\mu_{i j k}$, above). Approximate $P$ values could be presented by taking conservative estimates of the degrees of freedom although, given the volume of data available, this will typically lead to the detection of many statistically significant results that may not be biologically significant. Examining the full range of estimated coefficients across the random effects levels ensures that we present the full range of variation around global parameters and can make more informed inferences. In this way we encourage the reader to interpret our results by using biological insight, not by depending upon $P$ values alone.

To examine high-level differences in climate sensitivity among trophic levels and taxonomic groups, we re-fitted the LME model with these attributes as fixedeffect factors, interacting with the fixed-effect climate variables. The fixedeffect slopes from the resulting models allowed us to compare differences in phenological climate sensitivity among these broad organism groups, averaged across all taxa within each group. Supplementary Table 2 shows the number of phenological series, sites and distinct taxa that contributed data to each of these groups. All models were run twice: once to examine correlations with both temperature and precipitation excluding marine plankton data (9,800 time series), and once to examine only temperature-phenology correlations for the whole data set $(10,003$ time series).

Potential biases. Data availability differed among taxonomic groups. To assess the extent to which mean responses were biased by data inequality we conducted Monte Carlo re-sampling, iteratively selecting 5, 20, 50 and 100 phenological series from each taxonomic group and re-fitting climate-phenology models with these sampled data sets. For taxonomic groups with fewer data than the larger sample sizes, we retained all available data (see Supplementary Discussion). This allowed us to compare taxonomic group and trophic level responses based on sampled and all data, to fully investigate potential bias.

Another potential bias in our analysis is that phenological time series length is variable, affecting the length of time over which climate-phenology correlations are assessed. In order to assess the extent to which differences in mean trophic level and taxonomic group responses are biased by variable time series length, we also re-fitted our models but based only on pre- and post-1980 data. All models were run in the lme 4 package in $\mathrm{R}$ (refs 38,40 ).

Estimating future change. To estimate the potential future net effects of temperature and precipitation change, we compared predictions of seasonal timing under baseline conditions, and under established climate change scenarios. First, estimates of seasonal timing (day of year) were obtained for the same baseline period used in the UKCP09 projections (long term average 1961-1990), using modelled correlations between phenology, temperature and precipitation (from Phase 1). Having obtained these baseline estimates, we applied our models to projected changes in monthly temperature and precipitation for the 2050s (UK Climate Projections, UKCP09; http://ukclimateprojections.metoffice.gov.uk/). We used 10th, 50th and 90th percentile changes under low-, medium- and high-emissions scenarios (relative to the 1961-1990 baseline). The spatial location of each phenological series was matched to climate projection data for the $25 \times 25-\mathrm{km}$ grid square in which it occurred, and temporally matched to climatic data from the months of year in which its respective climate sensitivity windows occurred. Relative changes in timing, in response to climatic change of the magnitude projected to occur by the 2050s, were summarized by trophic levels and taxonomic groups.

Code availability. $\mathrm{R}$ code to run the described analyses can be found on GitHub (https://github.com/NERC-CEH/Phenology_Climate).

31. Perry, M. \& Hollis, D. The generation of monthly gridded data sets for a range of climatic variables over the UK. Int. J. Climatol. 25, 1041-1054 (2005).

32. Jones, I. D., Winfield, I. J. \& Carse, F. Assessment of long-term changes in habitat availability for Arctic charr (Salvelinus alpinus) in a temperate lake using oxygen profiles and hydroacoustic surveys. Freshw. Biol. 53, 393-402 (2008).

33. Elliott, J. M. Numerical changes and population regulation in young migratory trout Salmo trutta in a Lake District stream, 1966-83. J. Anim. Ecol. 53, 327-350 (1984).

34. Mohseni, O., Stefan, H. G. \& Erickson, T. R. A nonlinear regression model for weekly stream temperatures. Wat. Resour. Res. 34, 2685-2692 (1998).

35. Rayner, N. A. et al. Global analyses of sea surface temperature, sea ice, and night marine air temperature since the late nineteenth century. J. Geophys. Res. 108, 4407 (2003).

36. Reid, P. C., Colebrook, J. M., Matthews, J. B. L. \& Aiken, J. The Continuous Plankton Recorder: concepts and history, from Plankton Indicator to undulating recorders. Prog. Oceanogr. 58, 117-173 (2003).

37. Pope, K. S. et al. Detecting nonlinear response of spring phenology to climate change by Bayesian analysis. Glob. Change Biol. 19, 1518-1525 (2013).

38. R Development Core Team. R: A Language and Environment for Statistical Computing (2011).

39. Wood, S. N. Stable and efficient multiple smoothing parameter estimation for generalized additive models. J. Am. Stat. Assoc. 99, 673-686 (2004).

40. Bates, D., Maechler, M. \& Bolker, B. Ime4: Linear Mixed-Effects Models using S4 Classes (2011) 


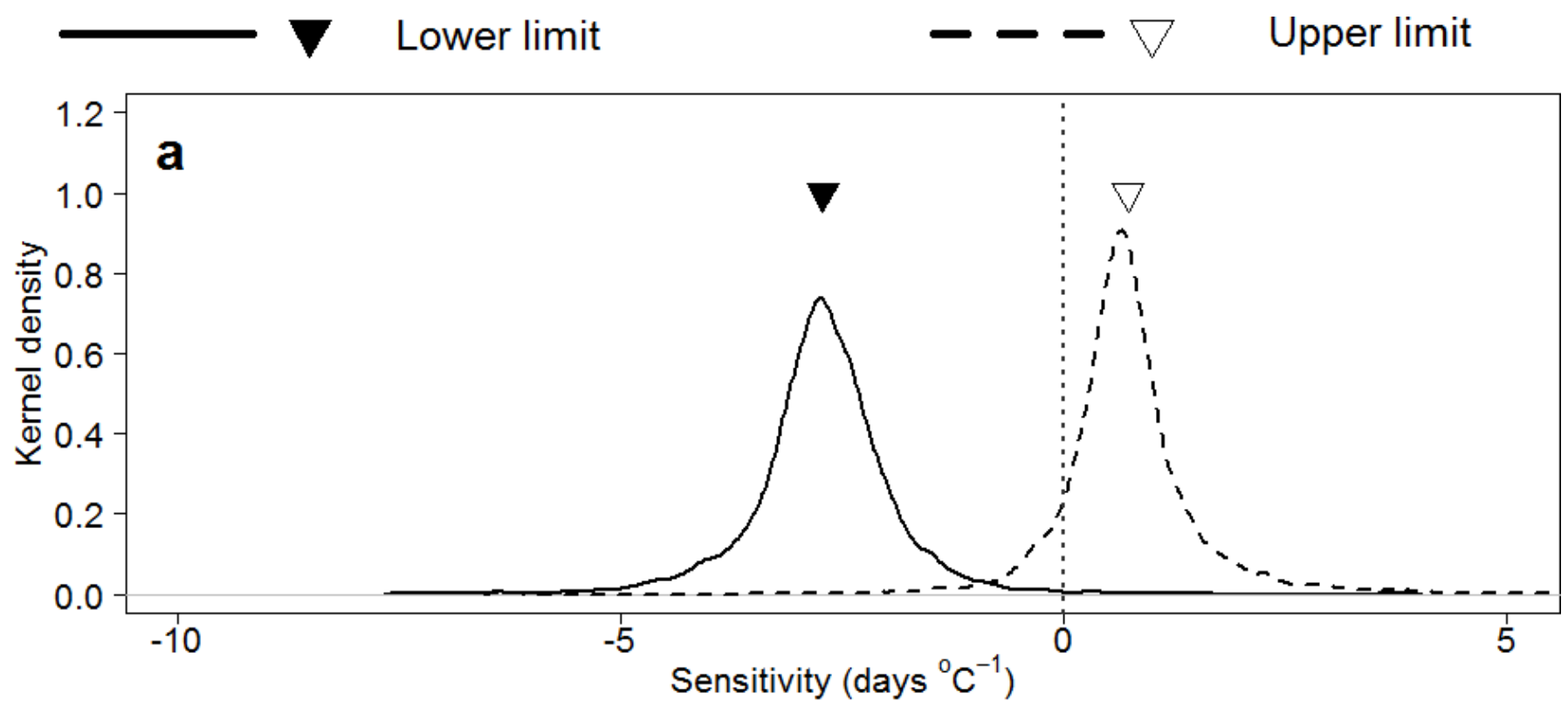

- Primary producer — Primary consumer — Secondary consumer

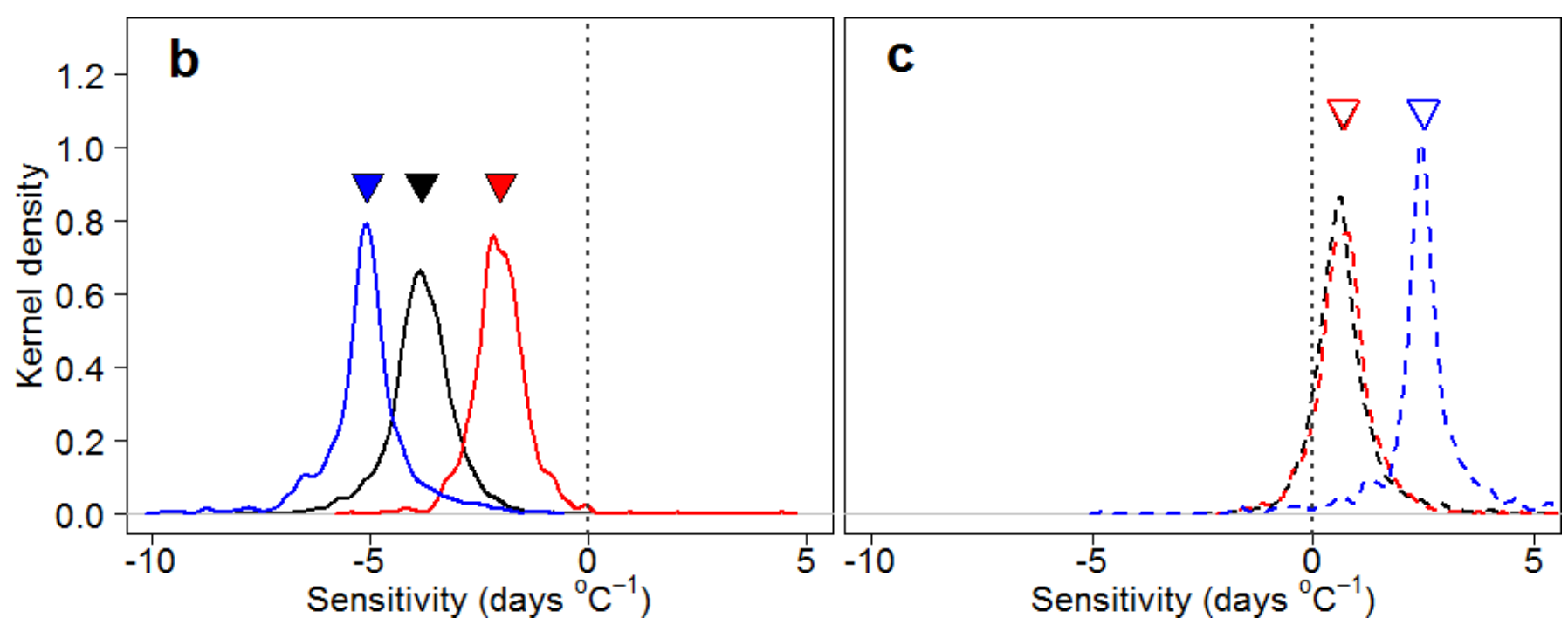

Extended Data Figure 1 | Limits of phenological temperature sensitivity inclusive of marine plankton data. a-c, Upper and lower limits of phenological temperature sensitivity are quantified as the slope of the relationship between seasonal timing (day of year) and temperature

$\left({ }^{\circ} \mathrm{C}\right)$ variation within specific seasonal periods. Limits in temperature

sensitivity are shown for all taxa (a) and by trophic level (lower limit, b; upper limit, c). Inverted triangles indicate average sensitivity for all species in each group and curves are probability density plots of species-level variation in sensitivity $(n=379,081)$. 


\section{Taxonomic groups}
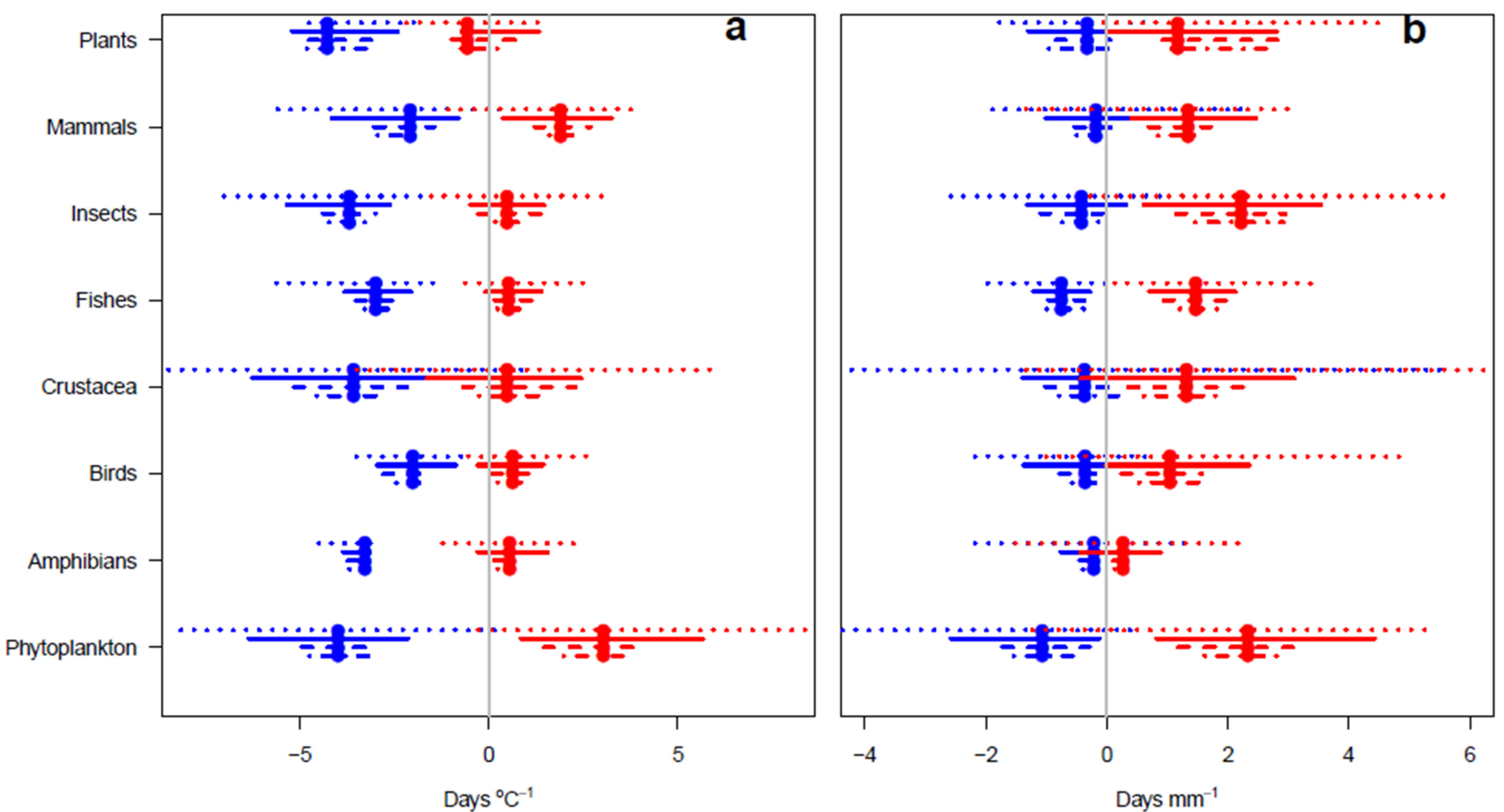

\section{Trophic levels}
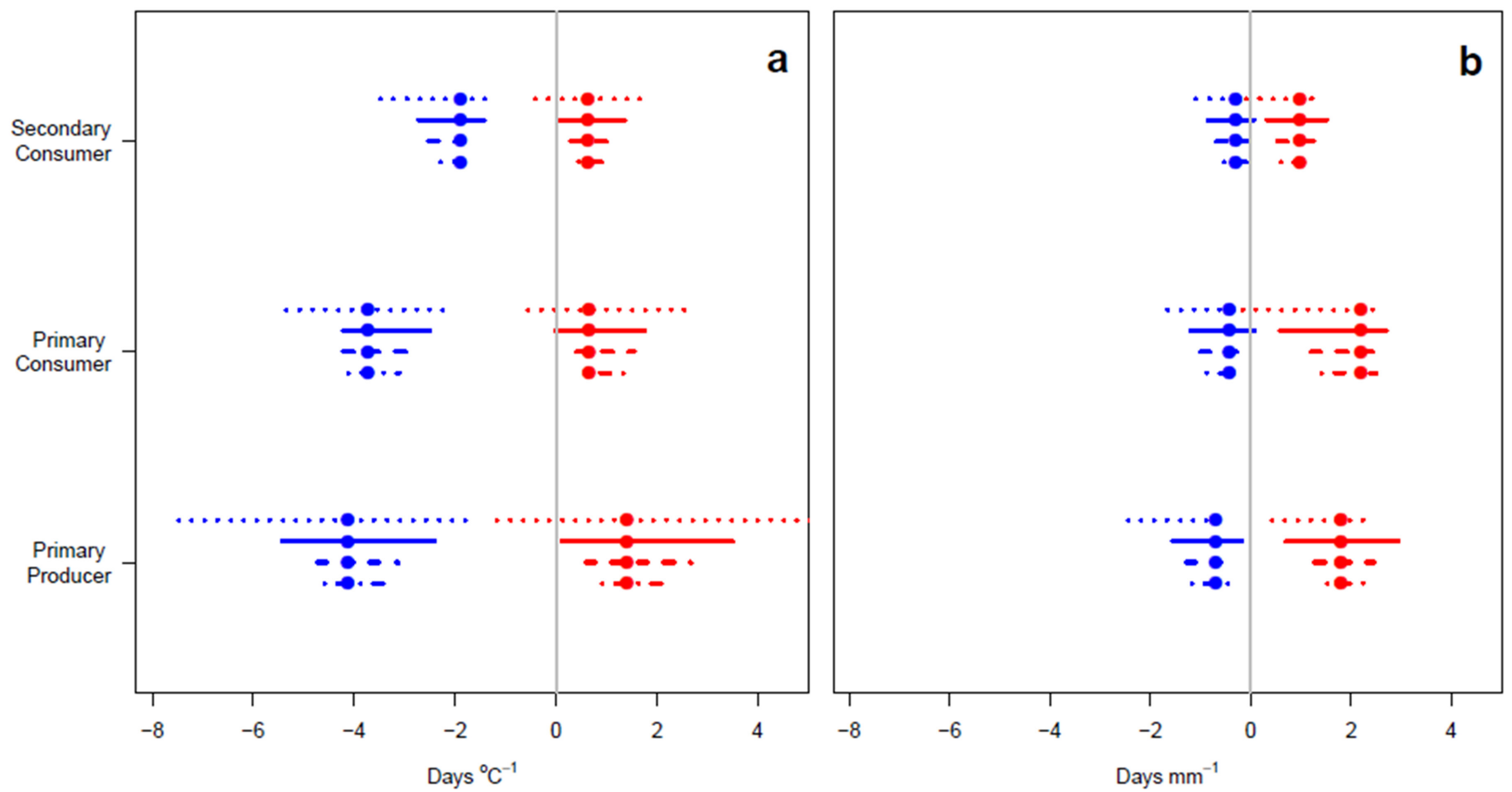

Extended Data Figure 2 Limits of phenological climate sensitivity for taxonomic groups (top) and trophic levels (bottom), after Monte-Carlo

Bars: 2.5th-97.5th percentile responses for each group, based upon 100 resampling. a, b, Lower (blue) and upper (red) limits of the sensitivity draws from the full data set. Data were sampled so that 5 , (dotted bar), 20 (solid bar), 50 (dashed bar) and 100 (dot-dashed bar) phenological of phenological events to changes in seasonal temperature (a) and time series were drawn from each taxonomic group $(n=370,725)$. precipitation (b). Coloured circles: responses based upon the full data set. 
All data

Pre-1980

data
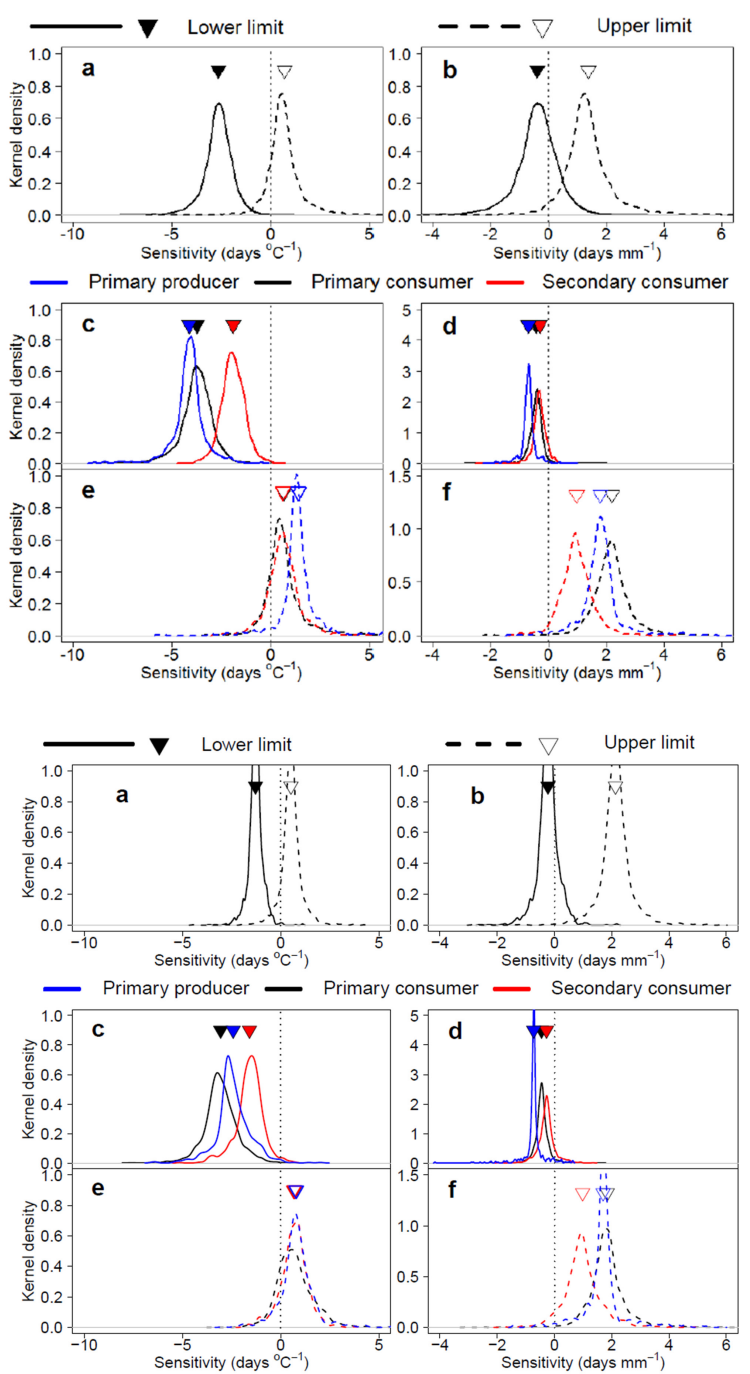

\section{Post-1980 data}
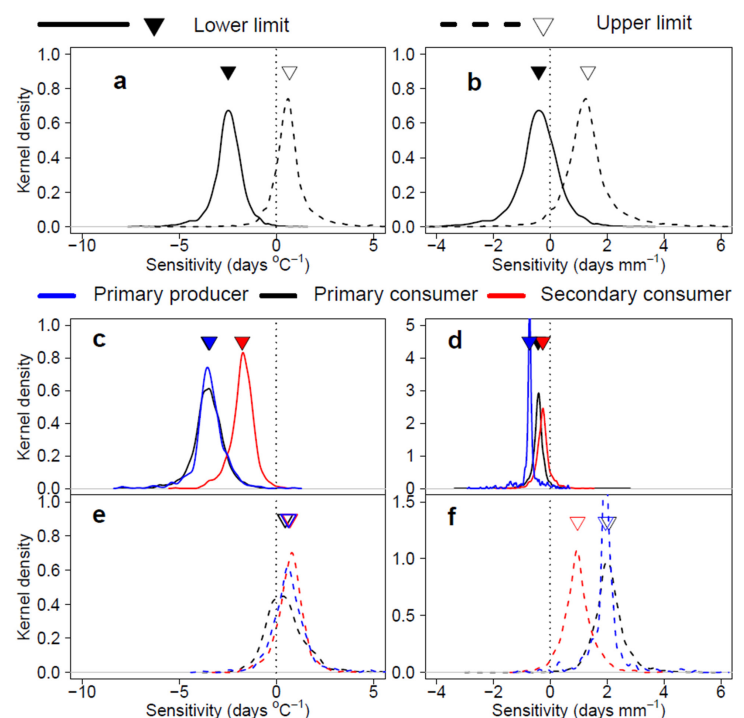

Extended Data Figure 3 | Climate sensitivities, based on different time periods. Top: all data; middle: pre-1980 data; bottom: post-1980 data. Sensitivity is the slope of the relationship between seasonal timing (day of year) and temperature $\left({ }^{\circ} \mathrm{C}\right)$ or precipitation (mm per day). a, b, Limits of temperature (a) and precipitation (b) sensitivity are summarized for all taxa. $\mathbf{c}-\mathbf{f}$, Lower $(\mathbf{c}, \mathbf{d})$ and upper (e, f) limits of temperature (c, e) and precipitation $(\mathbf{d}, \mathbf{f})$ sensitivity are shown by trophic level. Inverted triangles: average sensitivity for all species $(\mathbf{a}, \mathbf{b})$ or trophic levels $(\mathbf{c}-\mathbf{f})$. Curves, kernel density plots: probability density distributions of specieslevel climate sensitivity (that is, the relative likelihood of different climate sensitivities within each species group) $(n=370,725)$. 


\section{All data}
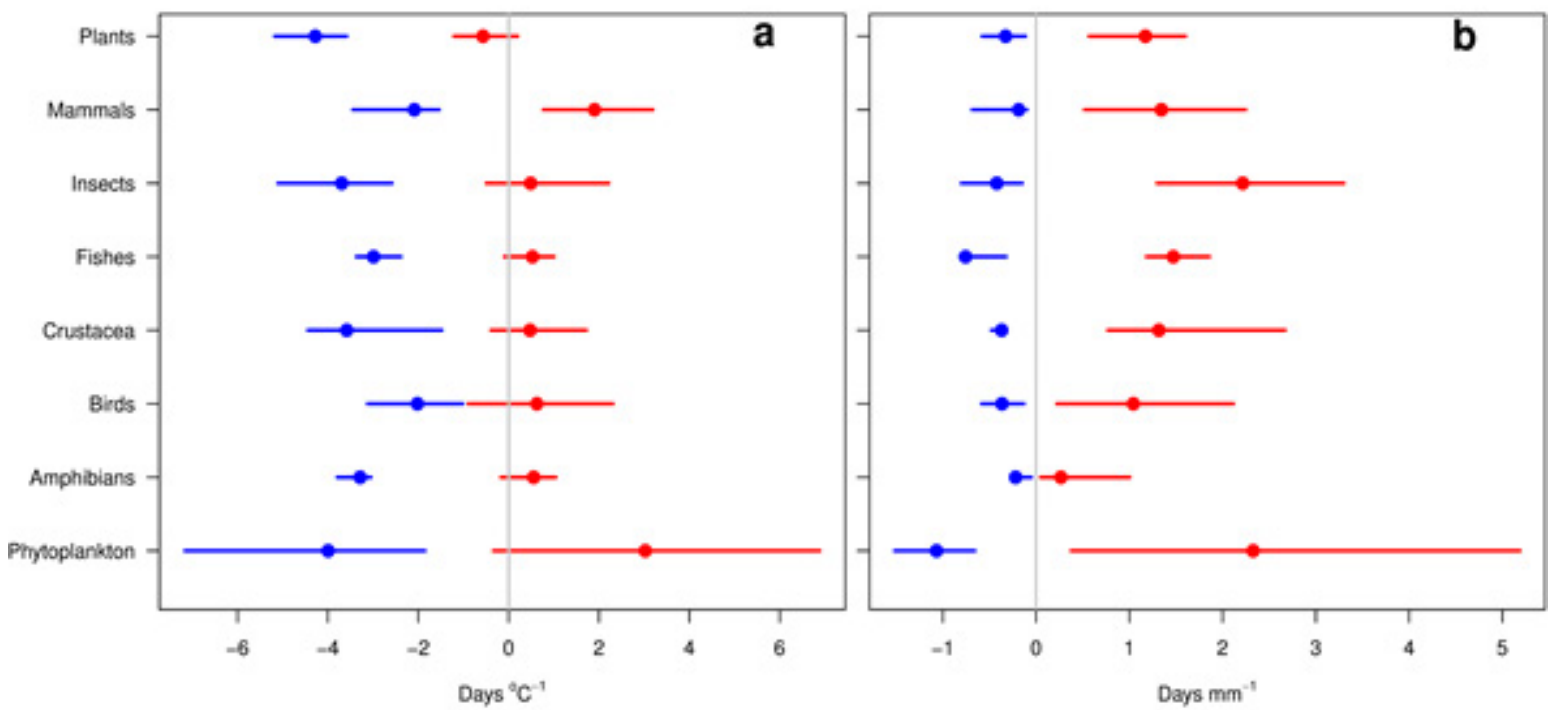

Post-1980 data
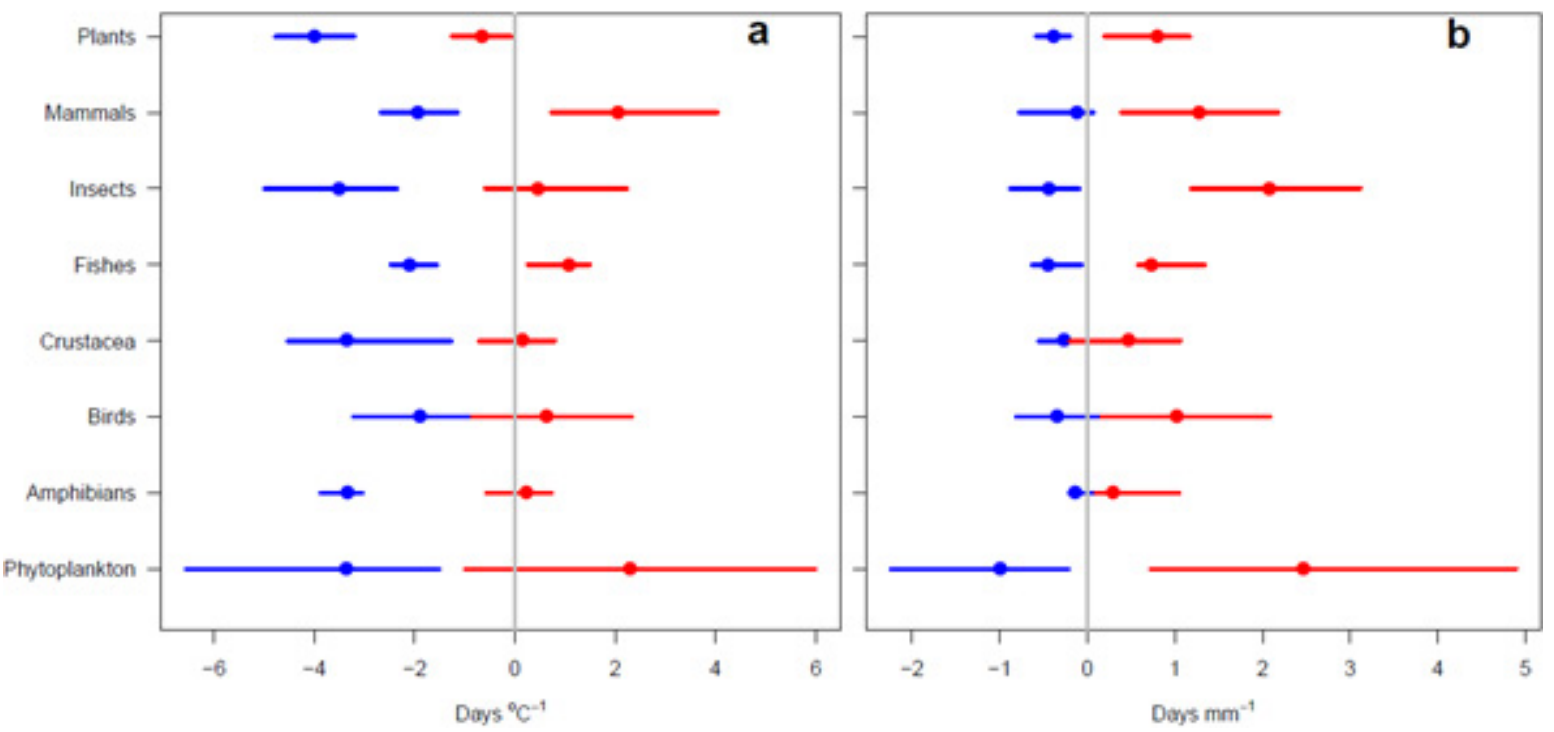

Extended Data Figure 4 | Limits of phenological climate sensitivity for broad taxonomic groups. Top, all data; bottom, post-1980 data only. a, b, Lower (blue) and upper (red) limits of the sensitivity of phenological events to seasonal temperature (a) and precipitation (b) change are shown. Coloured circles indicate the median response, and bars show the 5th-95th percentile responses for each group. Sensitivity is quantified by summarizing the species-level (random effects) responses from a mixed effects model including data for all taxa, and with taxonomic group as a fixed effect $(n=370,725)$. 


\section{RESEARCH ARTICLE}

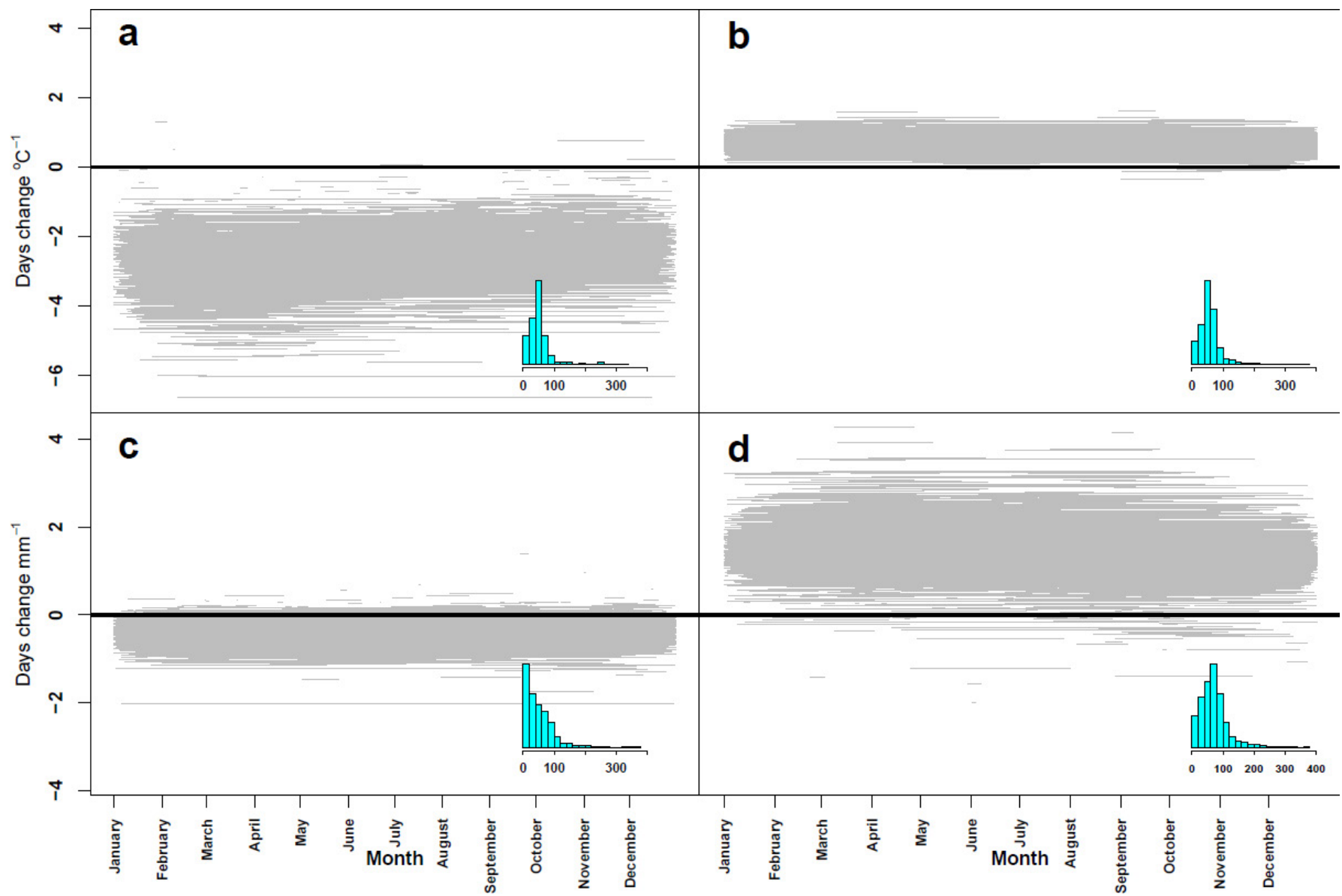

Extended Data Figure 5 | Seasonal windows for CSPs. a-d, Estimated climatic sensitivity at the lower $(\mathbf{a}, \mathbf{c})$ and upper $(\mathbf{b}, \mathbf{d})$ limits of CSPs for 10,003 phenological series. Grey lines are seasonal time periods ( $x$-axis) within which climatic variables have their most positive or negative correlations with the seasonal timing of each phenological event. The $y$-axis

indicates the slope coefficient for each of these correlations; a measure of climate sensitivity (days change per ${ }^{\circ} \mathrm{C}$ or per $\mathrm{mm}$ ). Shown are the lower and upper limits of $\mathrm{CSP}_{\text {temp }}$ ( $\mathbf{a}$ and $\mathbf{b}$, respectively) and the lower and upper limits of $\mathrm{CSP}_{\text {precip }}$ (c and $\mathbf{d}$, respectively). Inset histograms show seasonal time window length (days) $(n=370,725)$. 

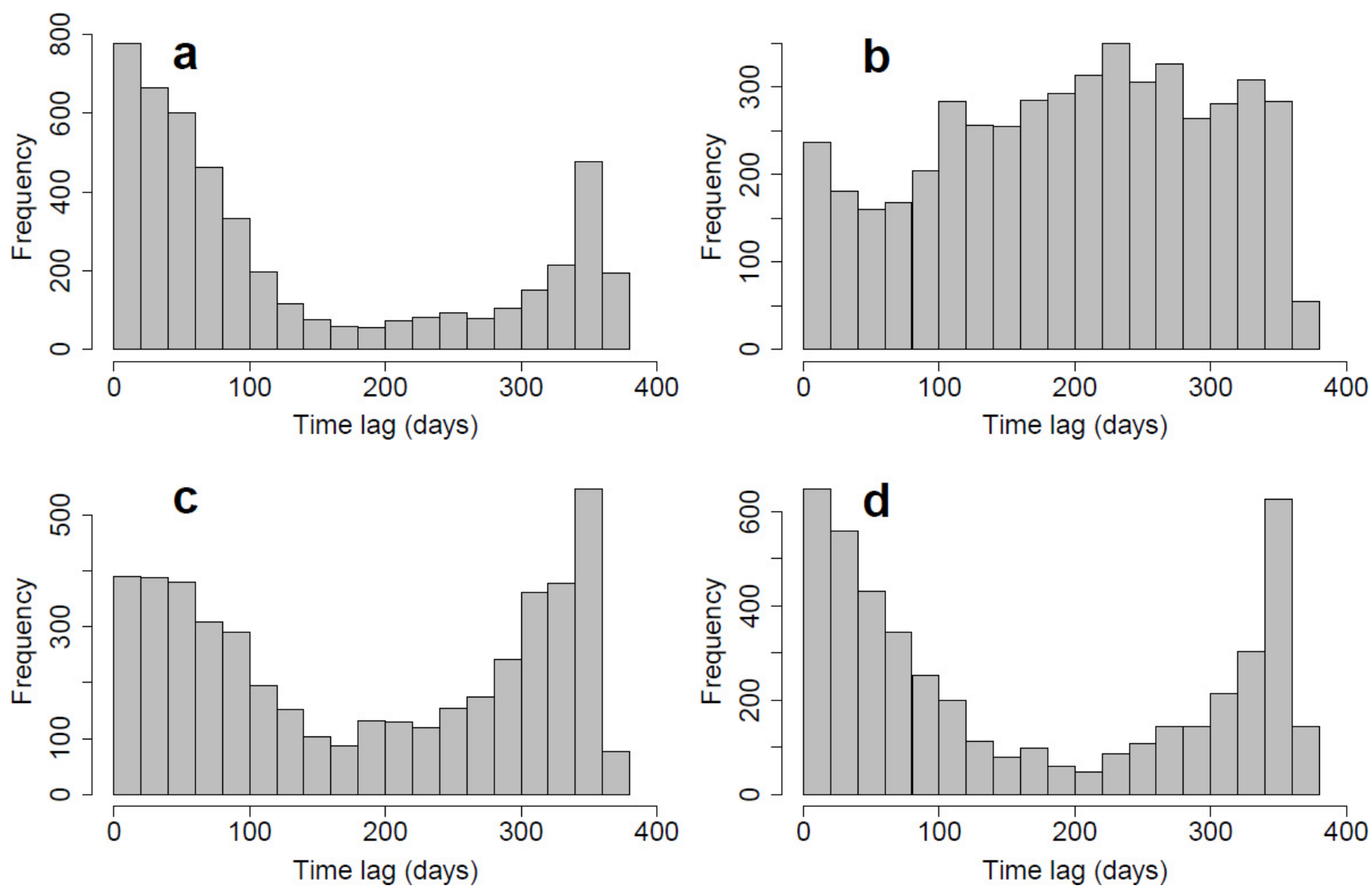

Extended Data Figure 6 | Time lags between phenological events and seasonal windows of climate sensitivity. a-d, Frequency histograms showing the time lag (in days) between the mean timing of each phenological event and the end of seasonal windows corresponding to the lower and upper limits of $\operatorname{CSP}_{\text {temp }}(\mathbf{a}$ and $\mathbf{b}$, respectively) and the

lower and upper limits of $\mathrm{CSP}_{\text {precip }}$ (c and $\mathbf{d}$, respectively). Peaks at lags of around 1 year are where windows were identified that ended at the mean seasonal timing of an event, but in the previous year, owing to temporal autocorrelation in climate data $(n=370,725)$. 


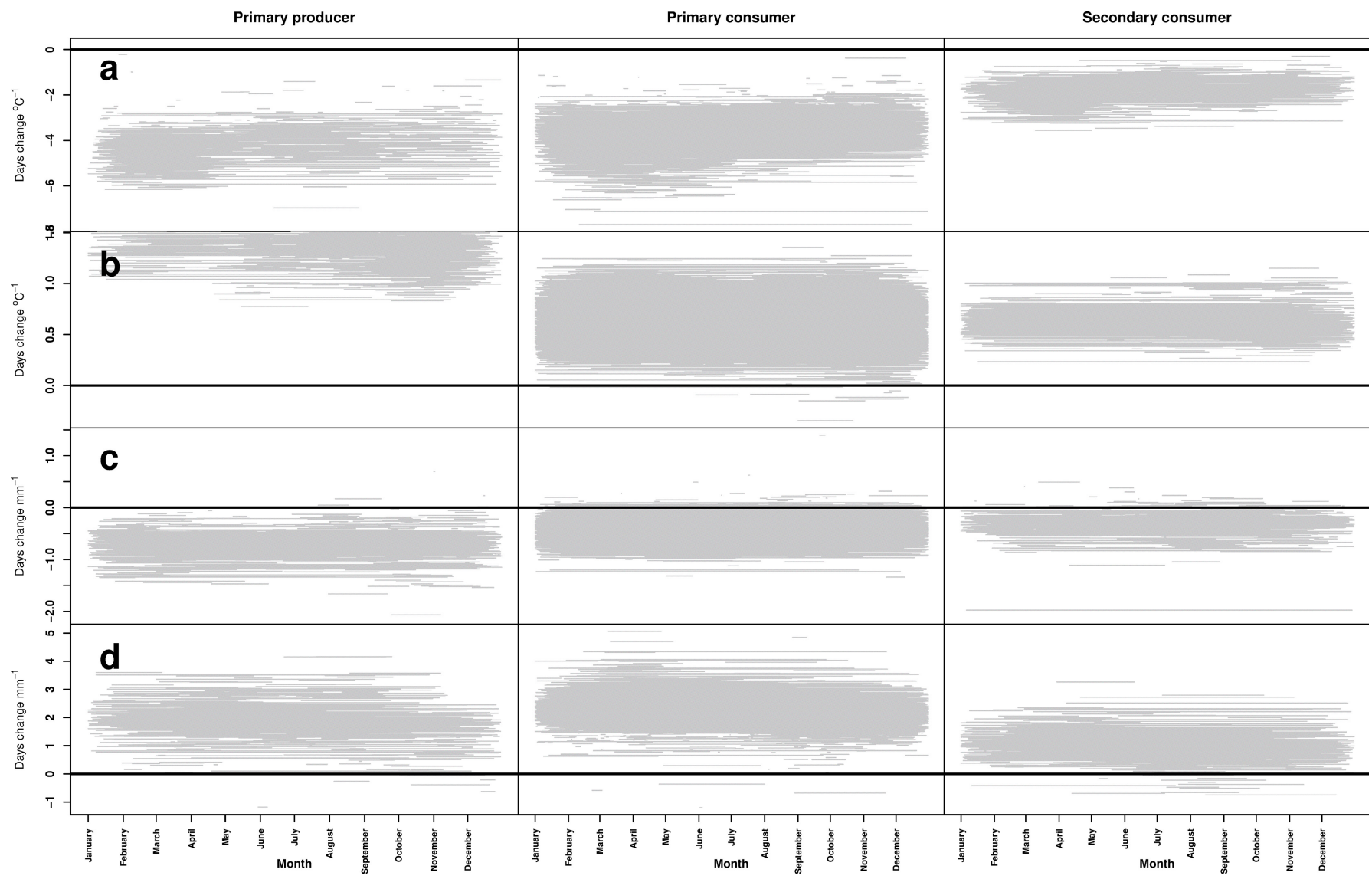

Extended Data Figure 7 | Seasonal windows for CSPs by trophic level. Estimated climatic sensitivity at the lower and upper limits of CSPs for taxa at each of three trophic levels. Formatting is as in Extended Data Fig. 5. a-d, Lower and upper limits of $\operatorname{CSP}_{\text {temp }}(\mathbf{a}$ and $\mathbf{b}$, respectively) and the lower and upper limits of $\operatorname{CSP}_{\text {precip }}$ (c and d, respectively) $(n=370,725)$. 


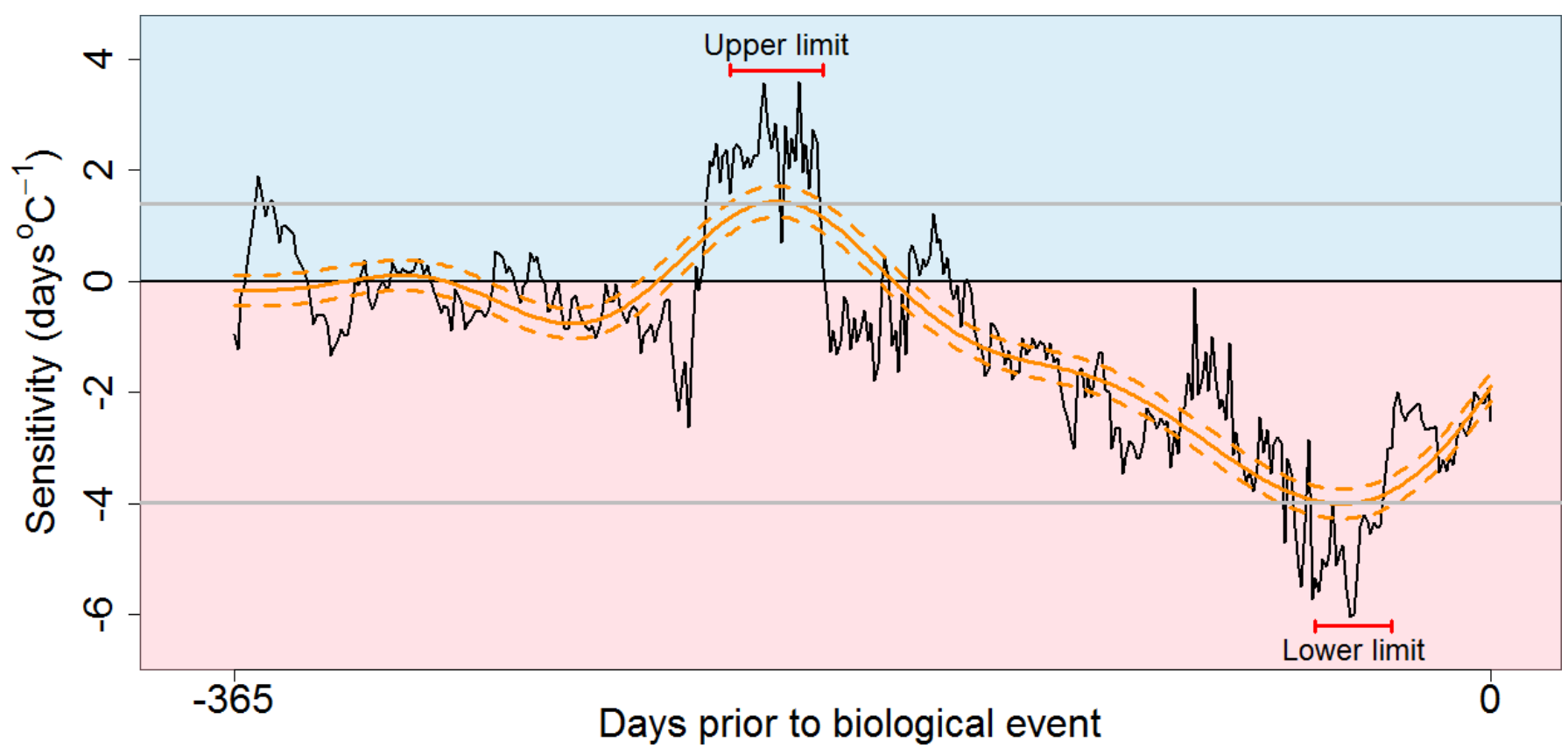

Extended Data Figure 8 | Example CSP. Temperature sensitivity (CSP temp) for alderfly (Sialis lutaria) emergence from Windermere, UK. Solid black line: sensitivity of first emergence to water temperature on different days of the year (days change per ${ }^{\circ} \mathrm{C}$ ). Grey horizontal lines: 2.5 th and 97.5 th percentiles of these sensitivity values. Solid orange curve: GAM smoother

fitted through the sensitivity values with associated confidence intervals (dashed orange curves). Horizontal bars indicate where GAM confidence intervals exceed the percentiles of the original sensitivity values, indicating seasonal windows at the limits of the climate sensitivity profile $(n=30)$. 


\section{RESEARCH ARTICLE}

Extended Data Table 1 | Modelled relationships between seasonal timing and climate variables for $n=10,003$ phenological time series

\begin{tabular}{|c|c|c|c|c|c|c|c|c|c|c|c|c|c|c|c|c|}
\hline & \multicolumn{3}{|c|}{ Whole data set } & \multicolumn{10}{|c|}{$\begin{array}{c}\text { Distribution of models among sensitivity types, for each } \\
\text { taxonomic group }\end{array}$} & \multicolumn{3}{|c|}{$\begin{array}{c}\text { Distribution of } \\
\text { models among } \\
\text { sensitivity types, } \\
\text { for each trophic } \\
\text { level }\end{array}$} \\
\hline $\begin{array}{l}\text { Climatic } \\
\text { variable }\end{array}$ & CSP type & $\begin{array}{c}\% \\
\text { series }\end{array}$ & $\begin{array}{c}\text { \% effects } \\
\text { significant } \\
\text { (lower, } \\
\text { upper) }\end{array}$ & 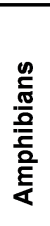 & $\frac{\text { on }}{\frac{0}{m}}$ & 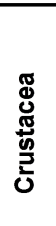 & $\frac{\frac{5}{\omega}}{\frac{\omega}{4}}$ & $\begin{array}{l}\text { 苞 } \\
\stackrel{\mathscr{g}}{\underline{S}}\end{array}$ & 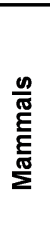 & 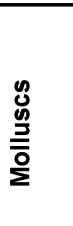 & 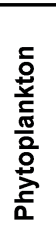 & $\begin{array}{l}\stackrel{0}{\frac{N}{5}} \\
\frac{\pi}{\alpha}\end{array}$ & $\begin{array}{l}\text { む̀ } \\
\text { 范 }\end{array}$ & $\begin{array}{l}\dot{8} \\
\text { ò } \\
\dot{2} \\
\dot{\varepsilon} \\
\dot{2}\end{array}$ & $\begin{array}{l}\dot{g} \\
\dot{0} \\
\dot{0} \\
\dot{\varepsilon} \\
\dot{2}\end{array}$ & $\begin{array}{l}\dot{0} \\
\dot{0} \\
0 \\
\dot{0} \\
\dot{\Phi} \\
\dot{0}\end{array}$ \\
\hline \multirow[t]{2}{*}{ Temperature } & Type I & 24.7 & $58.1,0.4$ & 27 & 21 & 19 & 45 & 26 & 27 & 20 & 12 & 20 & 24 & 16 & 26 & 21 \\
\hline & Type II & 69.7 & $44.8,1.0$ & 73 & 68 & 68 & 55 & 69 & 60 & 60 & 76 & 77 & 65 & 76 & 69 & 68 \\
\hline \multirow[t]{3}{*}{ Precipitation* } & Type I & 11.5 & $0.2,0.1$ & 27 & 16 & 0 & 18 & 11 & 5 & NAT & 11 & 13 & 10 & 11 & 11 & 16 \\
\hline & Type II & 53.0 & $0.1,0.6$ & 55 & 50 & 67 & 73 & 52 & 66 & NAT & 67 & 58 & 70 & 63 & 52 & 51 \\
\hline & Type III & 28.0 & $0.3,0.6$ & 9 & 22 & 14 & 0 & 30 & 22 & NAT & 18 & 23 & 17 & 21 & 30 & 22 \\
\hline
\end{tabular}

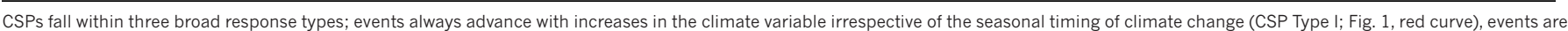
always delayed by increases in the climate variable irrespective of the seasonal timing of climate change (CSP Type III; Fig. 1, blue curve), and events may be advanced or delayed by increases in the climate variable, depending on the seasonal timing of climate change (CSP Type II; Fig. 1, orange curve). Shown are the percentage of series that fall in each type (\% series), the percentage of effects that are statistically significant at $P<0.05$ after multiple testing correction (\% effects significant). *Based only on freshwater and terrestrial taxa, for which precipitation data were available.

${ }^{\dagger} \mathrm{NA}$ indicates effect not evaluated, owing to lack of precipitation data for marine taxa. 
Extended Data Table 2 | Parameter estimates and test statistics from climate-phenology mixed-effects models

\begin{tabular}{|c|c|c|c|c|c|c|}
\hline & Response group & Intercept & Temp. Lower & Temp. Upper & Precip. Lower & Precip. Upper \\
\hline Global Model & All species & $169.1(1.7,98)$ & $-2.6(0.1,-35.2)$ & $0.7(0,14.1)$ & $-0.4(0,-13)$ & $1.4(0.1,19.4)$ \\
\hline \multirow[t]{3}{*}{$\begin{array}{l}\text { Trophic level } \\
\text { model }\end{array}$} & $\begin{array}{l}\text { Primary consumer } \\
\text { (b) }\end{array}$ & $211.6(1.6,131.1)$ & $-3.7(0.1,-39.5)$ & $0.7(0.1,10.6)$ & $-0.4(0,-11.8)$ & $2.2(0.1,23.7)$ \\
\hline & $\begin{array}{l}\text { Secondary } \\
\text { consumer }(\Delta b)\end{array}$ & $-67.5(2.5,-26.5)$ & $1.8(0.1,13.5)$ & $0.0(0.1,-0.2)$ & $0.1(0.1,1.9)$ & $-1.2(0.1,-8.7)$ \\
\hline & $\begin{array}{l}\text { Primary producer } \\
(\Delta b)\end{array}$ & $-50.9(5.7,-8.9)$ & $-0.4(0.3,-1.2)$ & $0.7(0.2,3.3)$ & $-0.3(0.1,-2.4)$ & $-0.4(0.3,-1.2)$ \\
\hline \multirow{8}{*}{$\begin{array}{l}\text { Taxonomic } \\
\text { Class model }\end{array}$} & Phytoplankton (b) & $199.2(6.9,28.9)$ & $-4.1(0.5,-7.8)$ & $2.9(0.2,12.2)$ & $-1.1(0.1,-7.6)$ & $2.5(0.5,5.4)$ \\
\hline & Amphibians $(\Delta b)$ & $-115.9(22.2,-5.2)$ & $0.7(1.2,0.6)$ & $-2.4(1.2,-1.9)$ & $0.9(1,0.9)$ & $-2.1(1.4,-1.5)$ \\
\hline & Birds $(\Delta b)$ & $-58.5(7.1,-8.2)$ & $2.0(0.5,3.8)$ & $-2.3(0.3,-9)$ & $0.7(0.2,4.6)$ & $-1.4(0.5,-3)$ \\
\hline & Crustacea $(\Delta b)$ & $-17.1(17.4,-1)$ & $0.9(0.9,1)$ & $-2.4(0.9,-2.6)$ & $0.7(0.3,2)$ & $-1.0(0.8,-1.2)$ \\
\hline & Fishes $(\Delta b)$ & $-41.3(23.8,-1.7)$ & $1.1(1.3,0.9)$ & $-2.4(1.2,-2)$ & $0.4(0.6,0.6)$ & $-1.0(1.2,-0.8)$ \\
\hline & Insects $(\Delta b)$ & $16.9(7,2.4)$ & $0.3(0.5,0.6)$ & $-2.3(0.2,-9.4)$ & $0.6(0.1,4.3)$ & $-0.3(0.5,-0.6)$ \\
\hline & Mammals $(\Delta b)$ & $43.8(10.9,4)$ & $1.9(0.7,2.7)$ & $-1.0(0.5,-1.9)$ & $0.8(0.3,2.6)$ & $-1.2(0.6,-1.8)$ \\
\hline & Plants $(\Delta b)$ & $-64.0(9.5,-6.8)$ & $-0.2(0.7,-0.3)$ & $-3.5(0.3,-11)$ & $0.7(0.2,2.9)$ & $-1.4(0.7,-2)$ \\
\hline $\begin{array}{l}\text { Global } \\
\text { Model }^{*}\end{array}$ & All species & $171.9(1.9,92.5)$ & $-2.7(0.1,-30.5)$ & $0.7(0.1,10.2)$ & & \\
\hline $\begin{array}{l}\text { Trophic level } \\
\text { model }^{\star}\end{array}$ & $\begin{array}{l}\text { Primary consumer } \\
(b) \\
\text { Secondary } \\
\text { consumer }(\Delta b) \\
\text { Primary producer } \\
(\Delta b)\end{array}$ & $\begin{array}{c}214.4(1.7,124.3) \\
-66.6(2.6,-25.3) \\
-49.5(5.2,-9.5) \\
\end{array}$ & $\begin{array}{l}-3.8(0.1,-31) \\
1.8(0.2,11.1) \\
-1.2(0.4,-3.4)\end{array}$ & $\begin{array}{l}0.7(0.1,6.9) \\
0.0(0.1,0.2) \\
1.8(0.3,5.8) \\
\end{array}$ & & \\
\hline
\end{tabular}

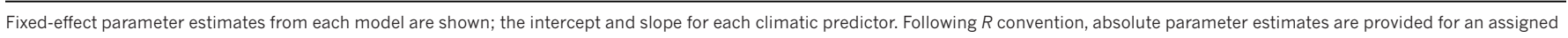
"baseline" group within each model (b), and remaining estimates are given as differences from this baseline $(\Delta b)$. Each estimate has an associated standard error and $t$ statistic in parentheses (standard error, $t$ ). Climatic predictors include mean temperature and precipitation in seasonal windows at the upper and lower limit of the climate sensitivity profile for each phenological series. The

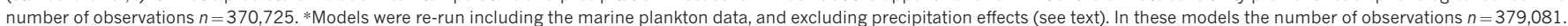

